\title{
In Parkinson's patient-derived dopamine neurons, the triplication of a-synuclein locus induces distinctive firing pattern by impeding D2 receptor autoinhibition
}

\author{
Min Lin ${ }^{1}$, Phillip M. Mackie ${ }^{1}$, Fatima Shaerzadeh ${ }^{1}$, Joyonna Gamble-George ${ }^{1}$, Douglas R. Miller ${ }^{1}$, \\ Chris J. Martyniuk ${ }^{2}$ and Habibeh Khoshbouei ${ }^{1^{*}}$ (i)
}

\begin{abstract}
Pathophysiological changes in dopamine neurons precede their demise and contribute to the early phases of Parkinson's disease (PD). Intracellular pathological inclusions of the protein a-synuclein within dopaminergic neurons are a cardinal feature of PD, but the mechanisms by which a-synuclein contributes to dopaminergic neuron vulnerability remain unknown. The inaccessibility to diseased tissue has been a limitation in studying progression of pathophysiology prior to degeneration of dopamine neurons. To address these issues, we differentiated induced pluripotent stem cells (iPSCs) from a PD patient carrying the a-synuclein triplication mutation (AST) and an unaffected first-degree relative (NAS) into dopaminergic neurons. In human-like dopamine neurons a-synuclein overexpression reduced the functional availability of D2 receptors, resulting in a stark dysregulation in firing activity, dopamine release, and neuronal morphology. We back-translated these findings into primary mouse neurons overexpressing a-synuclein and found a similar phenotype, supporting the causal role for a-synuclein. Importantly, application of D2 receptor agonist, quinpirole, restored the altered firing activity of AST-derived dopaminergic neurons to normal levels. These results provide novel insights into the pre-degenerative pathophysiological neuro-phenotype induced by a-synuclein overexpression and introduce a potential mechanism for the long-established clinical efficacy of D2 receptor agonists in the treatment of PD.
\end{abstract}

Keywords: a-synuclein, iPSCs, Dopamine neurons, D2 receptor, Parkinson's disease

\section{Introduction}

Progressive loss of dopaminergic neurons with corresponding increases in $\alpha$-synuclein characterize many Parkinson's disease (PD) cases [20, 47, 131]. Triplication of the SNCA locus encoding $\alpha$-synuclein leads to a penetrant form of PD and degeneration of dopamine

\footnotetext{
*Correspondence: Habibeh@ufl.edu

${ }^{1}$ Department of Neuroscience, University of Florida, Gainesville, FL 32611, USA

Full list of author information is available at the end of the article
}

neurons, suggesting a causal role for $\alpha$-synuclein in the degeneration process. However, the underlying mechanisms of progressive neuronal loss remain nebulous. Consequently, there is no cure for PD, only therapeutic strategies to alleviate the symptoms of disease. Dopamine replacement strategies are the first choice of treatment and one of the most common pharmacological strategies to sustain the quality of life in PD patients [2, 4, 34, 35, 103, 106, 133]. Specifically, dopamine D2-like receptors (D2R) have historically been one of the primary therapeutic targets. Pre-synaptic D2Rs tightly regulate dopaminergic neuronal activity [11, 19, 23, 37, 56, 90, original author(s) and the source, provide a link to the Creative Commons licence, and indicate if changes were made. The images or other third party material in this article are included in the article's Creative Commons licence, unless indicated otherwise in a credit line to the material. If material is not included in the article's Creative Commons licence and your intended use is not permitted by statutory regulation or exceeds the permitted use, you will need to obtain permission directly from the copyright holder. To view a copy of this licence, visit http://creativecommons.org/licenses/by/4.0/. The Creative Commons Public Domain Dedication waiver (http://creativeco mmons.org/publicdomain/zero/1.0/) applies to the data made available in this article, unless otherwise stated in a credit line to the data. 
96], and previous reports have shown the impairment of D2 receptor-dependent dopaminergic transmission in parkinsonian animal models [74]. In addition, treatment with dopamine D2 receptor agonists restored decreased precursor cell proliferation in parkinsonian animal models [51] and attenuated the compulsive behaviors associated with reduced striatal D2R expression in PD patients [121]. However, despite widespread study in preclinical models and clinical use, the mechanisms underlying D2R-mediated regulation of neuronal activity in the context Parkinson's Disease-particularly before extensive nigral neuron loss-are not fully understood.

Due to the inaccessibility of diseased tissue, critical investigation into the progression of PD pathophysiology prior to degeneration of dopamine neurons remains improbable. In addition, although several PD animal models have been established, most of these models have failed to reproduce the human disease in its entirety $[42,99,105]$. Recent advances in differentiating human induced pluripotent stem cells (iPSCs) provide a promising tool to investigate the pathological events in human cells that lead to neuronal demise, disease modeling [7, 53], and drug screening [43, 50]. Differentiated iPSCs of parent cells derived from patients harboring diseaserelated genes have been generated, specifically those related to early onset PD [111, 119], or healthy individuals into the functional dopaminergic neurons [109]. The accessibility of iPSC-derived dopamine neurons from both a PD patient harboring $\alpha$-synuclein triplication and their unaffected first-degree relative (neurotypical control) provide a disease-relevant system to study how excess $\alpha$-synuclein leads to neuronal dysfunction. In 2011, the Kunath lab [32] generated sets of iPSC lines from a PD patient with triplication of SNCA, and an unaffected first-degree relative, which serves as a control with a similar genetic background to minimize phenotypic differences not due to the triplication of SNCA [32]. The PD patient-derived cells with $\alpha$-synuclein triplication are referred to AST cells and the healthy relative-derived cells with normal $\alpha$-synuclein are referred to NAS cells.

In this study, we differentiated the AST and NAS iPS cell lines to human-like dopamine neurons [32, 80]. Similar to published reports, we found that after 30-36 days of differentiation, the AST- and the NAS-derived cells developed neuronal like morphology and expressed the markers of dopaminergic neurons such as tyrosine hydroxylase $(\mathrm{TH})$ and dopamine transporter (DAT) $[32,80]$. Importantly, almost all neuronal-like cells were silent, meaning they did not exhibit spontaneously firing activity, which is a hallmark of dopaminergic neuronal phenotype. After 150 days of differentiation, 98\% of human iPSC-derived neurons were observed to express all expected dopaminergic neuronal markers and importantly, these neurons were electrically mature with self-initiated firing activity, recapitulating the canonical dopaminergic neuronal phenotype. Via a double blinded experimental design, we report that $\alpha$-synuclein overexpression, in both human-like iPSC-derived and primary mouse dopamine neurons, induces a unique firing pattern characterized by prolonged broadbrimmed bursts. Furthermore, we show that activation of D2R restores the firing pattern to baseline. Collectively our findings provide new insight into the pathophysiological events induced by $\alpha$-synuclein and the mechanisms underlying the benefit of D2R agonists in Parkinson's disease.

\section{Results}

Inaccessibility of diseased tissue for mechanistic studies prior to neuronal demise creates major barrier to research on Parkinson's disease. Induced pluripotent stem cells (iPSCs) differentiated toward a dopaminergic neuronal phenotype offer a valuable source to generate human dopaminergic neurons. In this study, we differentiated two iPSC lines obtained from a patient with $\alpha$-synuclein triplication (AST) and an unaffected firstdegree relative (NAS), each of which were differentiated into dopamine neurons [32]. The overall goal of this study was to examine $\alpha$-synuclein modulation of human dopamine neuronal activity prior to neuronal demise.

\section{Expression of human dopaminergic neuron markers and a-synuclein}

As outlined in Fig. 1a, iPSCs were differentiated to dopaminergic neurons. To confirm that human iPSC-derived neurons expressed canonical dopaminergic neuronal markers, we used co-immunofluorescent labeling for either tyrosine hydroxylase $(\mathrm{TH})$ and dopamine transporter (DAT), or co-labeling for $\alpha$-synuclein and $\mathrm{TH}$ at an early differentiation stage (Fig. 1b). To identify whether $\alpha$-synuclein overexpression affects the expression of dopaminergic neuronal markers, we utilized methodologies described in previous reports $[21,28,78,129]$ to quantitatively analyze the immunoreactivity of these markers. Quantifying average fluorescence intensity suggested increased immunoreactivity for $\alpha$-synuclein in the AST-derived neurons and decreased immunoreactivity for DAT and TH (Additional file 1: Fig. S1). To verify complete neuronal differentiation, we surveyed the expression of canonical indicators for neuronal maturation such as Nurr1, FOXA2 and MAP2, followed by immunostaining for dopaminergic markers. The orphan nuclear receptor-related factor 1 (Nurr1) is involved in the development of midbrain dopamine neurons [137]. FOXA2 is a member of the Foxa subfamily of forkhead/ winged helix transcription factors [3] and is required for the expression of Nurr1 in immature midbrain dopamine 


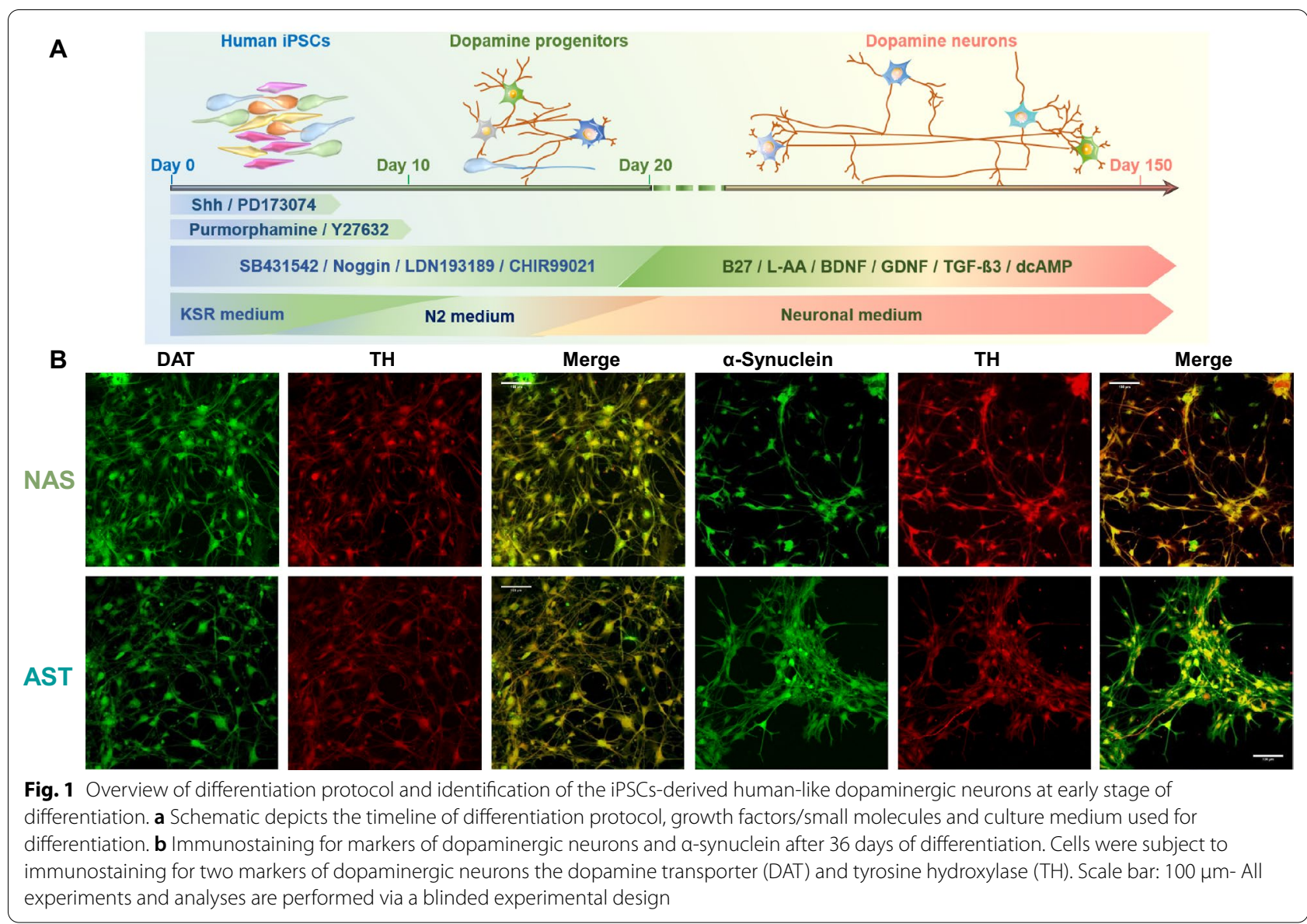

neurons and for the differentiation to mature midbrain dopamine neurons [36]. MAP2 provides information on cytoskeletal structure, specific to neurons $[87,15,24$, 31]. Genes encoding Parkin (PRK8, [64] and $\alpha$-synuclein [100], have been linked to familial PD [113]. Therefore, we performed parallel immunostaining using identical solutions and imaging resolution to examine immunoreactivity for Nurr1, FOXA2, MAP2 and PRK8, (Fig. 2a). Consistent with previous data [32], we found all of these markers are expressed in both human-like dopamine neurons with normal $\alpha$-synuclein levels (NAS) and $\alpha$-synuclein triplication (AST). Notably, PRK8 is clearly detectable in AST-derived dopamine neurons, but only scattered punctate staining is detected in NAS-derived dopamine neurons (Fig. 2a). In addition, calculating the average fluorescence intensity for each marker suggested decreased immunoreactivity of MAP2, FOXA2, and Nurr1 (Additional file 1: Fig. S1).

The development of ventral midbrain dopamine neurons involves multiple parallel, controlled processes encompassing many transcription factors tightly coordinated in order to produce functional midbrain neurons [6]. Several factors have been identified and used to determine the fate of midbrain dopaminergic neurons in the embryonic brain, including Lmx1a [5], Msx1 [5], Foxa2 [36], En-1 [115], Lmx1b [117], Pax2/ Pax5 [128], Otx2 [1], Gli1 [136], tyrosine hydroxylase [114], Slic6a3 [8], and Nurr1 [137]. We next investigated the transcript expression levels of these markers in the fully differentiated AST- and NAS-derived dopamine neurons using qPCR (Fig. $2 \mathrm{~B}, \mathrm{n}=6$ from three independent rounds of differentiation). Our results showed that the transcription factors outlined above were expressed in both NAS- and AST-derived dopamine neurons. Consistent with previous reports [98], [32], transcript levels for $\alpha$-synuclein were increased in AST-derived dopamine neurons $(\mathrm{n}=6$ from three independent rounds of differentiation, two-tailed paired t-test, $p=0.04$ ), whereas, the transcript levels for transcription factors OTX2 and GLI1 as well as for canonical markers $\mathrm{TH}$, dopamine transporter, GIRK2 channels and Nurr 1 were decreased (Fig. 2, $\mathrm{n}=6$ from three independent rounds of differentiation, two-tailed paired t-test, $p=0.0006)$. Notably, the transcript levels for D2 receptor were increased in the AST-derived dopamine neurons, but the mRNA levels for KCNJ6G, 


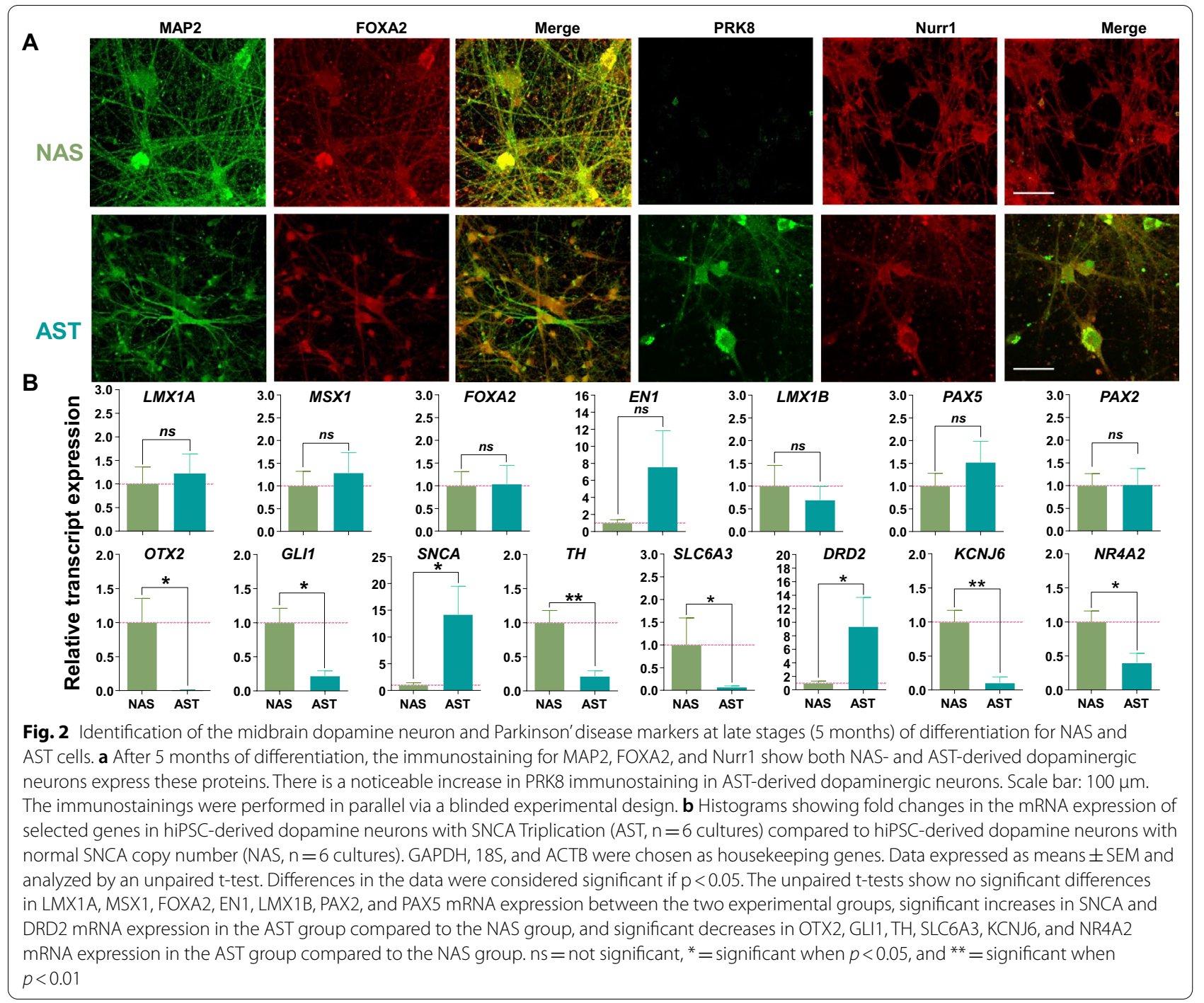

a gene encoding G-protein activated inward rectifier potassium channel 2 (GIRK2) were decreased $(n=6$ from three independent rounds of differentiation, twotailed paired t-test, $p=0.04)$. Notably, a shared limitation of qPCR and immunocytochemistry is that one cannot ascertain the membrane levels or the activity of these membrane-embedded receptors. Nevertheless, collectively, these data suggest that our differentiation protocol produces human iPSC-derived dopaminergic neurons expressing their appropriate markers. Although the results shown in this study have been reproducible in multiple rounds of differentiation, one of the limitations of this study is that they are conducted in two iPSC lines, normal and $\alpha$-synuclein triplication lines. a-synuclein-overexpressing dopamine neurons exhibit a unique pattern of spontaneous firing activity with a pause between subsequent broadbrimmed bursts To further elucidate the pathophysiological effects of $\alpha$-synuclein on dopamine neurons, we next examined the intrinsic firing behavior of NAS- and AST-derived dopamine neurons after 5 months of neuronal differentiation. A total of 157 iPSC-derived dopamine neurons from three independent rounds of differentiation were recorded and analyzed for the experiments outlined below. Experiments and analyses were performed under a blinded experimental design. The primary parameters of passive membrane were averaged for each NAS and AST group. The average input resistance was $312.4 \pm 58.4$ $\mathrm{M} \Omega$ in NAS and $135.7 \pm 16.6 \mathrm{M} \Omega$ in AST $(p=0.003$, 
two-tailed Student's t tests); the membrane time constant was $897.8 \pm 61.7 \mu$ s in NAS and $918.2 \pm 54.7$ in AST ( $p=0.802$, two-tailed Student's t tests); and the membrane capacitance was $66.4 \pm 4.5 \mathrm{pF}$ in NAS and $88.4 \pm 6.0 \mathrm{pF}$ in AST ( $p=0.005$, two-tailed Student's t tests).

Previous studies report on the firing behavior of wild type (WT) rodent dopamine neurons [12, 46, 48, 52, $55,75,76,84,108,110,124]$ and have shown WT dopamine neurons exhibit both pacemaker-like firing activity and burst firing with an average rate of $0.5-10 \mathrm{~Hz}$ [46]. Studies also demonstrate a broader range of spontaneous spike frequency of $0-20 \mathrm{~Hz}$ in dopamine neurons [66]. In this study, we found the majority of NAS-derived dopamine neurons exhibited a mixture of single spikes and small burst activity with an underlying "pacemakerlike" periodicity. The pacemaker-like firing activity and canonical irregular single-spike firing occurred at rates of 1-4 Hz. Bursts of 3-8 spikes occurred at higher frequencies with a pause between subsequent bursts with a varied interspike interval (Fig. 3a1), whereas the majority of AST-derived dopamine neurons ( $90 \%$ i.e., 25 of 28 recorded neurons) exhibited a unique high up-state (depolarized plateau) and high frequency of spontaneous activity with a pause between subsequent broadbrimmed bursts (Fig. 3a2). The burst range was $5-25 \mathrm{~Hz}$ (average: $11.6 \pm 1.4 \mathrm{~Hz})$ with $30-300$ spikes $(118.1 \pm 19.8$ spikes) in $5-25 \mathrm{~s}$ duration (11.2 $\pm 1.5 \mathrm{~s}, \mathrm{n}=27$ /group).

To determine whether increased $\alpha$-synuclein in ASTderived dopamine neurons is the underlying mechanism for the observed firing behaviors, we measured the firing activity of WT and $\alpha$-synuclein-overexpressing mouse midbrain dopamine neuronal culture. Consistent with previous reports $[12,13,52,75,76,108,110]$, the firing pattern of cultured mouse dopamine neurons is a mixture of single spikes and small burst activity with an

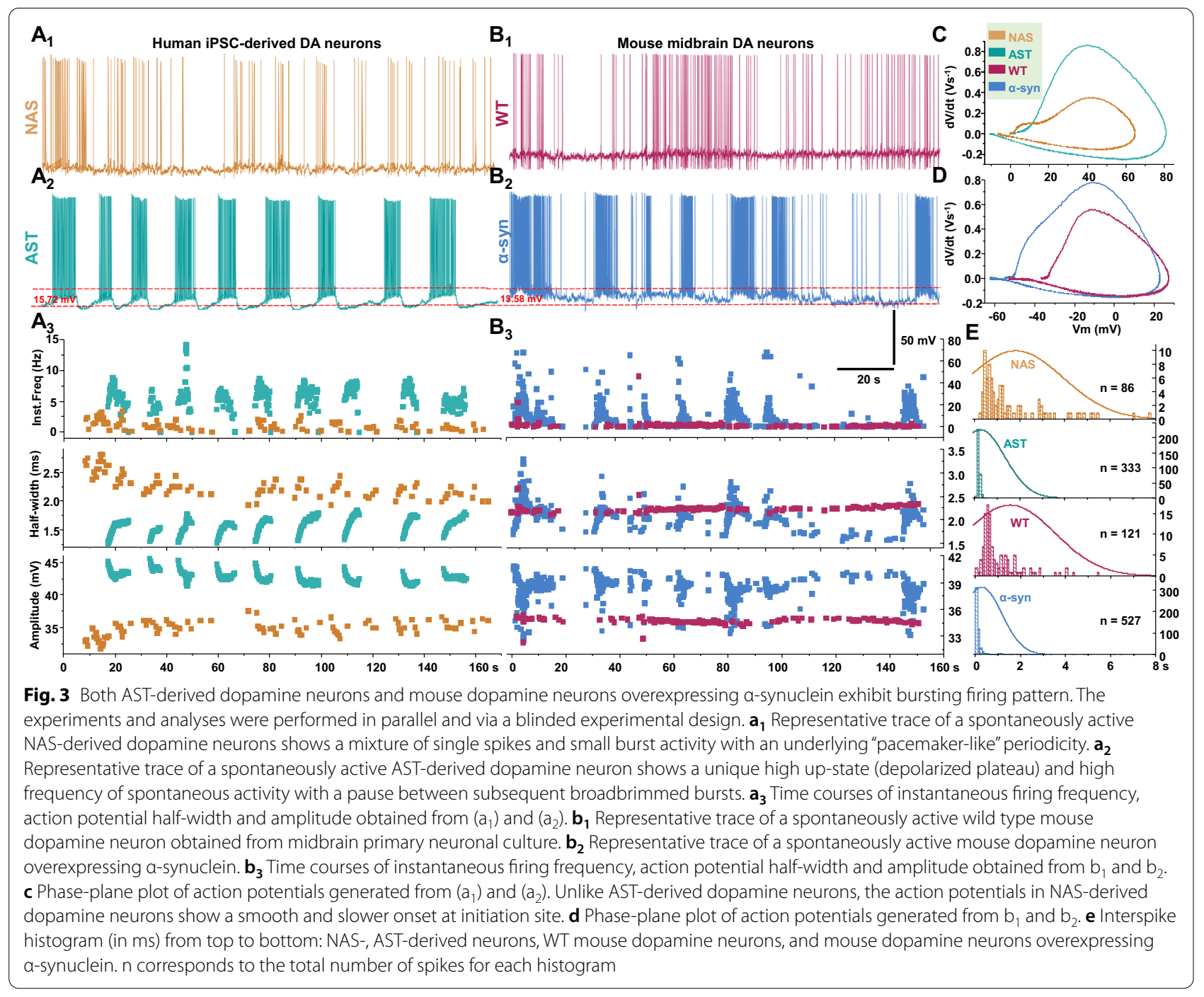


underlying "pacemaker-like" periodicity that is similar to the firing activity of NAS-derived dopamine neurons (Fig. 3b1). Similar to the firing pattern measured in the AST-derived dopamine neuron, in mouse dopamine neurons overexpressing $\alpha$-synuclein, the frequency of spontaneous firing activity is increased (Fig. 3a3, b3), coupled with a depolarized plateau (high up-state, Fig. 3a2, b2) and a pause between broadbrimmed bursts (Fig. 3b2).

The phase plot is generated when change in the time derivative of the voltage $(\mathrm{dV} / \mathrm{dt})$ is plotted against the membrane potential $\mathrm{V}(\mathrm{t})[58,91]$. Examining the phase plot shapes for the action potential upstroke (Fig. 3c, d) revealed the rate of membrane potential change in the AST-derived dopamine neurons (Fig. 3c) is similar to $\alpha$-synuclein-overexpressing mouse dopamine neurons (Fig. 3d). Additionally, the action potential onsets in NAS-derived dopamine neurons (Fig. 3c) and WT mouse dopamine neurons (Fig. 3d) are relatively slower at the initiation site. The interspike interval (ISI) distribution is a commonly used criterion to determine if burst activity is present in single neurons [83, 91]. The ISI of an NAS-derived dopamine neuron and dopamine neuron from a WT mouse are randomly distributed within 0.2-6 s (Fig. 3e). Conversely, the range of ISI distribution in an AST-derived dopamine neuron and an $\alpha$-synucleinoverexpressing mouse dopamine neuron fall in a narrower ranged below $1 \mathrm{~s}$ (Fig. 3e). Overall, these data indicate that increases in $\alpha$-synuclein alter the pattern of intrinsic firing activity in both human iPSC-derived dopamine neurons and mouse dopamine neurons.

\section{Increased a-synuclein levels underly the altered intrinsic firing behavior of AST-derived dopamine neurons}

To investigate the underlying mechanism of altered intrinsic firing behavior of dopamine neurons induced by excess $\alpha$-synuclein levels, we compared the distribution of individual ISI in the AST-derived versus NASderived neurons as well as in $\alpha$-synuclein-overexpressing mouse dopamine neurons versus WT dopamine neurons (Fig. $4 \mathrm{a}-\mathrm{d}$ ). The $50 \%$ probability of ISI in AST-derived dopamine neurons (Fig. $4 \mathrm{a}, \mathrm{n}=16$ ) and $\alpha$-synucleinoverexpressing dopamine neurons (Fig. $4 b, n=13$ ) were below $0.5 \mathrm{~s}$. In contrast, the $50 \%$ probability of ISI in NAS-derived neurons and WT dopamine neurons were over $1 \mathrm{~s}$. Accordingly, analysis of individual dopamine neuron for firing frequency exhibited the $50 \%$ probability of instantaneous frequency were below $10 \mathrm{~Hz}$ in NAS-derived neurons and below $5 \mathrm{~Hz}$ in WT dopamine neurons. In comparison, the $50 \%$ probability of instantaneous frequency were over $10 \mathrm{~Hz}$ in both AST-derived dopamine neuron and mouse dopamine neurons overexpressing $\alpha$-synuclein (Fig. 4c, d).
To elucidate alterations in patterns of firing activity beyond average firing rate, we evaluated firing activity for bursting features, defined as periods of high frequency firing of a neuron separated by periods of quiescence, which has been observed in various neuronal systems, both in vitro and in vivo [25, 46, 82]. A wide variety of computational approaches have been developed to detect periods of bursting in spike trains. We used the algorithm developed by Grace and Bunney [46] to compare bursting in dopamine neurons with native vs. increased $\alpha$-synuclein levels. Burst onsets were defined by two consecutive spikes with an ISI $<80 \mathrm{~ms}$ and terminated when the ISI was $>160 \mathrm{~ms}$. Spikes that occurred within the burst are expressed relative to the total number of spikes from the same neuron (\%SWB) [46]. Burst analysis revealed that $28.5 \pm 4.2 \%$ of spikes in NAS-derived dopamine neurons were within bursts. In striking contrast, $93.2 \pm 2 \%$ of spikes in the AST-derived neurons were within a burst (\%SWB, Fig. 4e, m). Similarly, mouse dopamine neurons overexpressing $\alpha$-synuclein produced a much higher percentage of spikes fired in bursts (\%SWB, $81.2 \pm 3.7 \%$, range of $40 \%$ to $97 \%$ in individual neurons) compared to WT dopamine neurons (\%SWB, $20.0 \pm 1.9 \%$, range of $8 \%$ to $47 \%$ in individual neurons) (Fig. $4 \mathrm{f}, \mathrm{m}$ ). Further examination of membrane potential during periods of quiescence and bursting revealed significant relative changes in up-state potential. Up-state refers to the membrane potential during a firing burst, which is depolarized relative to quiescent periods, known as down-states [73]. The up-state was increased in both AST-derived neurons and mouse dopamine neurons overexpressing $\alpha$-synuclein $(\mathrm{NAS}=5.91 \pm 1.0 \mathrm{mV} \quad$ vs. $\quad \mathrm{AST}=14.13 \pm 1.1 \mathrm{mV}$, $p<0.001$,WT mouse $=4.88 \pm 0.3 \mathrm{mV}$ vs. mouse dopamine neurons overexpressing $\alpha$-synuclein $=10.54 \pm 0.7 \mathrm{mV}$, $p<0.001$, Fig. $4 \mathrm{~g}, \mathrm{~h}, \mathrm{n})$. Increased up-state was coupled to a higher firing frequency $(\mathrm{NAS}=1.04 \pm 0.2 \mathrm{~Hz}$ vs. $\mathrm{AST}=2.46 \pm 0.4 \quad \mathrm{~Hz}, \quad p=0.011$,WT mouse $=1.04 \pm 0.2 \mathrm{~Hz}$ vs. mouse dopamine neurons overexpressing $\alpha$-synuclein $=2.36 \pm 0.2 \quad \mathrm{~Hz}$, $p<0.001$, Fig. 4l), with a larger coefficient-of-variation $(\mathrm{NAS}=2.70 \pm 0.3$ vs. $\mathrm{AST}=5.11 \pm 0.6, \quad p=0.002$,WT mouse $=1.58 \pm 0.2$ vs. mouse dopamine neurons overexpressing $\alpha$-synuclein $=2.19 \pm 0.2, p=0.03$, Fig. $4 \mathrm{k}$ ). Additionally, the up-state in AST-derived dopamine neurons (Fig. 4g, n) or mouse dopamine neurons overexpressing $\alpha$-synuclein (Fig. 4h, n) revealed higher frequencies of distribution. Finally, examination of action potential morphology showed the AST-derived dopamine neurons exhibited a significantly shorter half-width of action potential (2.12 $\pm 0.16 \mathrm{~ms}$, Fig. 4I) and higher amplitude (35.17 $\pm 1.7 \mathrm{mV}$ Fig. 4 j) compared to NAS-derived dopamine neurons (half-width: $3.11 \pm 0.36 \mathrm{~ms}, p=0.015$, halfamplitude: $29.3 \pm 1.16 \mathrm{mV}$, one-way ANOVA, $p=0.005$, 


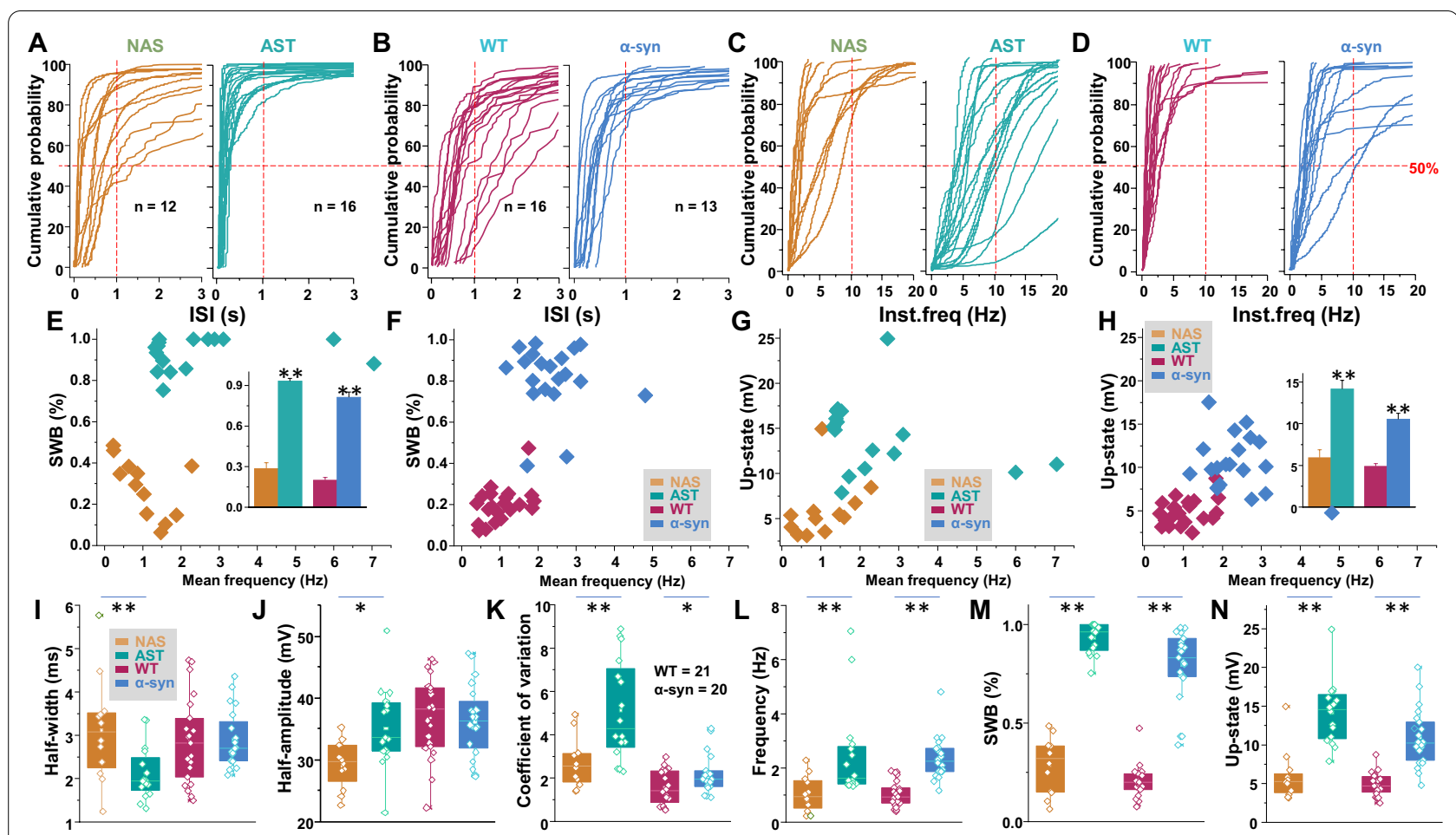

Fig. 4 Analyses of firing-pattern and intrinsic firing properties of NAS-, AST-derived neurons, WT mouse dopamine neurons, and mouse dopamine neurons overexpressing a-synuclein. The experiments and analyses were performed in parallel via a blinded experimental design. a left: Interspike interval (ISI) distribution in NAS-derived dopamine neurons. Each curve in individual panels represents cumulative probability for an individual neuron, the $50 \%$ probability was below $1 \mathrm{~s}$. Right: ISI distribution in AST-derived dopamine neurons, the 50\% probability was below $0.25 \mathrm{~s}$. b Left: ISI distribution of WT mouse dopamine neurons, the 50\% probability was below $2 \mathrm{~s}$. Right: ISI distribution observed in mouse dopamine neurons overexpressing a-synuclein. The $50 \%$ probability was below $0.5 \mathrm{~s}$. c Left: Instantaneous frequency distribution obtained from NAS-derived neurons; the $50 \%$ probability was below $10 \mathrm{~Hz}$. Right: Instantaneous frequency distribution obtained from AST-derived neurons; the 50\% probability was below $20 \mathrm{~Hz}$. d Left: Instantaneous frequency distribution of WT mouse dopamine neurons, the $50 \%$ probability was below $5 \mathrm{~Hz}$. Right: Instantaneous frequency distribution of mouse dopamine neurons overexpressing a-synuclein, the $50 \%$ probability was below $10 \mathrm{~Hz}$. e Mean firing frequency ( $\mathrm{Hz}$ ) against percentage of spike within a burst (\%SWB) for NAS- and AST-derived dopamine neuron groups. Inset shows increased a-synuclein in the neurons enhanced \%SWB in both iPSC-derived human-like dopamine neurons and mouse dopamine neurons. f Mean firing frequency against \%SWB for WT mouse dopamine neurons, and mouse overexpressing a-synuclein. $\mathbf{g}$ and $\mathbf{h}$ Mean firing frequency against up-state for NAS- and AST-derived dopamine neurons, or WT mouse dopamine neurons against mouse dopamine neurons overexpressing a-synuclein. Inset shows a higher amplitude of up-state in both AST-derived dopamine neurons and mouse dopamine neurons overexpressing a-synuclein. I. The spike half-width of AST-derived dopamine neurons $(n=16)$ is shorter than NAS-derived neurons $\left(n=12, F_{(3,65)}=3.744, p=0.015\right.$, one-way ANOVA). $\mathbf{j}$ The spike half-amplitude of AST-derived neurons is higher than NAS-derived neurons $\left(F_{(3,65)}=4.681, p=0.005\right.$, one-way ANOVA). $\mathbf{k}$ interspike intervals are calculated over 1 min of spontaneous firing activity, the coefficients of variation of the interspike interval are significantly larger in either AST-derived dopamine neurons or mouse dopamine neurons overexpressing a-synuclein compared to NAS-derived dopamine neurons or WT mouse dopamine neurons $\left(F_{(3,63)}=21.39, P<0.0001\right.$. one-way ANOVA). I Compared to NAS-derived dopamine neurons or WT mouse dopamine neurons, the spontaneous firing rates are higher in AST-derived dopamine neurons or mouse dopamine neurons overexpressing a-synuclein $\left(F_{(3,}\right.$ ${ }_{65}=10.67, P<0.0001$, one-way ANOVA). $\mathbf{m}$ Compared to their counterpart experimental group, the percentage of spike within a burst is higher in AST-derived dopamine neurons or mouse dopamine neurons overexpressing a-synuclein $\left(F_{(3,67)}=160.8, P<0.0001\right.$, one-way ANOVA). $\mathbf{n}$ The up-state is significantly higher in either AST-derived dopamine neurons or mouse dopamine neurons overexpressing a-synuclein, compared to their counterpart experimental groups containing endogenous a-synuclein level $\left(F_{(3,67)}=34.57, P<0.0001\right.$, one-way ANOVA)

Fig. 4i, j). Collectively, these data suggest increased $\alpha$-synuclein levels modulates the intrinsic firing behavior of both AST-derived human like dopamine neurons and mouse dopamine neurons overexpressing $\alpha$-synuclein.
Activation of dopamine $D 2$ receptors reinstates the firing activity of AST- to NAS-derived dopamine neurons levels Previous studies have shown that activation or inhibition of dopamine D2 receptors (D2Rs) tightly regulates the firing activity of dopamine neurons $[11,19,23,37,56,90$, 96]. Decreased functionality or inhibition of D2 receptors produces a distinct firing pattern that is described by increased up-state leading to a higher firing frequency of 
dopamine neurons, which is similar to what we measured in the AST-derived dopamine neurons and mouse dopamine neurons overexpressing $\alpha$-synuclein. Therefore, we reasoned that the distinct firing pattern observed in these neurons (Figs. 3, 4) might be due to the decreased functional availability of D2R. To test this possibility, we activated D2 receptors on AST-derived dopamine neurons (Fig. 5a1) or mouse dopamine neurons overexpressing $\alpha$-synuclein (Fig. 5a2) using the D2R agonist quinpirole $(5 \mu \mathrm{M})$. Bath application of quinpirole dispersed broadbrimmed firing burst into NAS-derived or WT mouse dopamine neurons-like, smaller bursts intermingled single spikes (brown trace for AST-derived neurons, wine trace for mouse neurons overexpressing $\alpha$-synuclein). Although quinpirole did not affect the action potential onset (Fig. 5c, d), the ISI distribution was restored to the time window measured in NAS-derived (Fig. 5e3) and WT dopamine neuron levels (Fig. 5f3).
We investigated the distribution of individual ISI in AST-derived dopamine neurons and mouse dopamine neurons overexpressing $\alpha$-synuclein (Fig. 6a, b) before and during bath application of quinpirole $(5 \mu \mathrm{M})$. Quinpirole shifted the $50 \%$ cumulative probability of ISI from low to high values in both AST-derived dopamine neurons (Fig. 6a) and mouse dopamine neurons overexpressing $\alpha$-synuclein (Fig. 6b). Similarly, quinpirole decreased the $50 \%$ cumulative probability of instantaneous firing frequency (Fig. 6c, d). In addition, quinpirole decreased the \%SWB, average firing frequency, and the magnitude of up-state in both AST-derived dopamine neurons and mouse dopamine neurons overexpressing $\alpha$-synuclein (Fig. 6i-n). Specifically, in AST-derived dopamine neurons \%SWB decreased from $95.1 \pm 2 \%$ to $48.8 \pm 4.9 \% \quad(p<0.001$, $\mathrm{n}=11$, Fig. 6e inset, $\mathrm{m})$. In mouse dopamine neurons overexpressing $\alpha$-synuclein, \%SWB decreased from $80.6 \pm 5.5 \%$ to $48.2 \pm 8.9 \%(p=0.004, \mathrm{n}=12)$ (Fig. 6f,

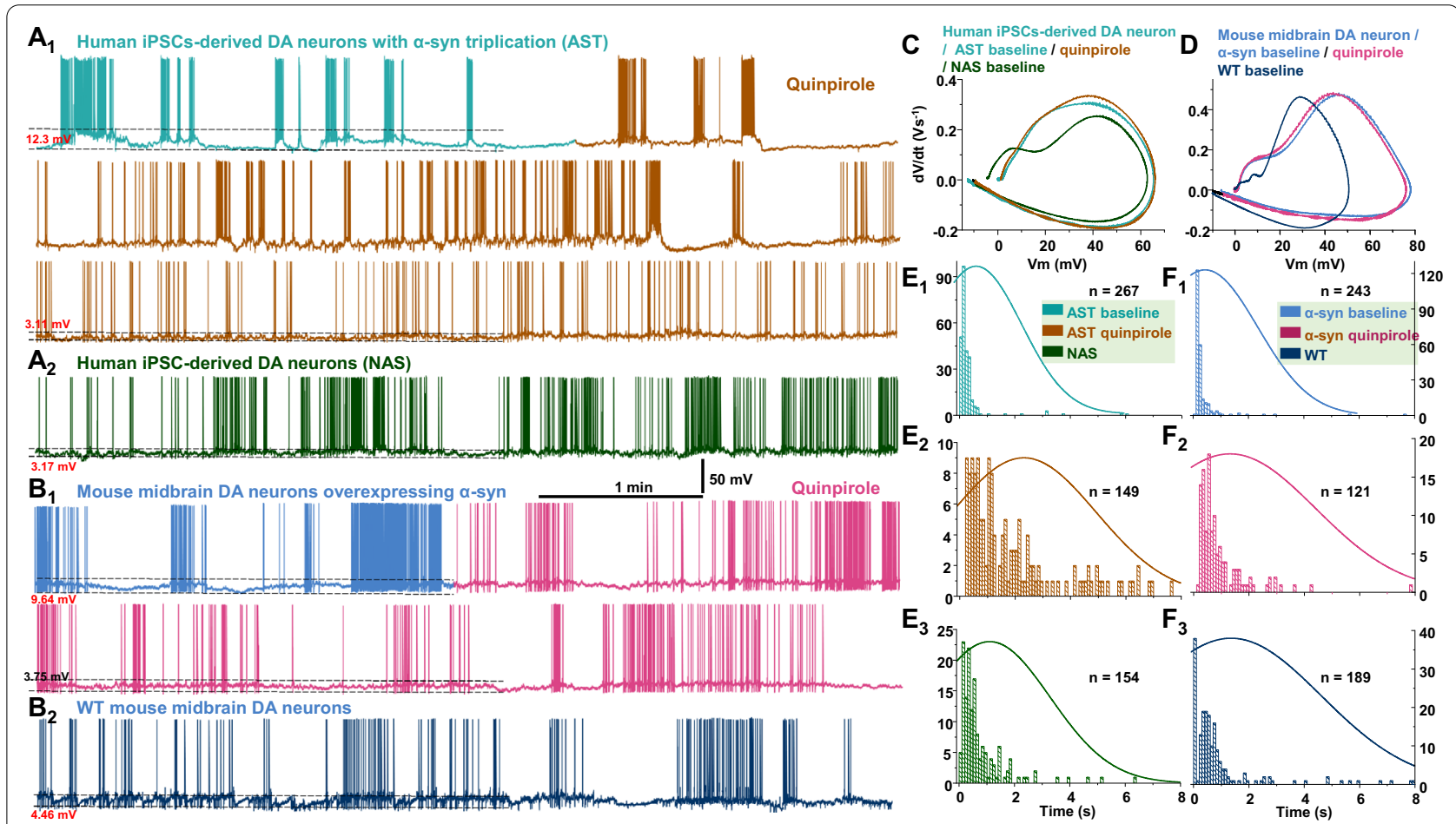

Fig. 5 Agonist activation of D2R reduces the size of clustered burst firing in AST-derived dopamine neurons or mouse dopamine neurons overexpressing a-synuclein. The experiments and analyses were performed in parallel and via a blinded experimental design. $\mathbf{a}_{1}$ Representative recording of a spontaneously active AST-derived dopamine neuron before (aqua blue) and during (brown) application of quinpirole. $\mathbf{a}_{2}$ Representative trace of a spontaneously active NAS-derived dopamine neurons shows a mixture of single spikes and burst activity. $\mathbf{b}_{1}$ Representative recording of a spontaneously active mouse dopamine neuron overexpressing a-synuclein before (navy-blue) and during (wine) application of quinpirole. $\mathbf{b}_{\mathbf{2}}$ Representative trace of a spontaneously active wild type mouse dopamine neuron obtained from midbrain primary neuronal culture. $\mathbf{c}$ Phase-plane plot of action potentials generated from $\left(\mathbf{a}_{\mathbf{1}}\right)$ and $\left(\mathbf{a}_{\mathbf{2}}\right)$. $\mathbf{d}$ Phase-plane plot of action potentials generated from $\left(\mathbf{b}_{1}\right)$ and $\left(\mathbf{b}_{\mathbf{2}}\right)$ e Interspike histogram (in ms) of human iPSCs-derived dopamine neurons for three conditions belonging, from top to bottom: AST-derived neurons at baseline $\left(\mathbf{e}_{1}\right)$, during quinpirole application $\left(\mathbf{e}_{2}\right)$ and NAS baseline $\left(\mathbf{e}_{3}\right)$. $\mathbf{f}$ Interspike histogram (in ms) of mouse midbrain dopamine neurons for three conditions belonging, from top to bottom: overexpressing a-synuclein at baseline $\left(\mathbf{f}_{1}\right)$, during quinpirole application $\left(\mathbf{f}_{\mathbf{2}}\right)$ and WT baseline $\left(\mathbf{f}_{\mathbf{3}}\right)$. n corresponds to the total number of spikes to determine the histogram 


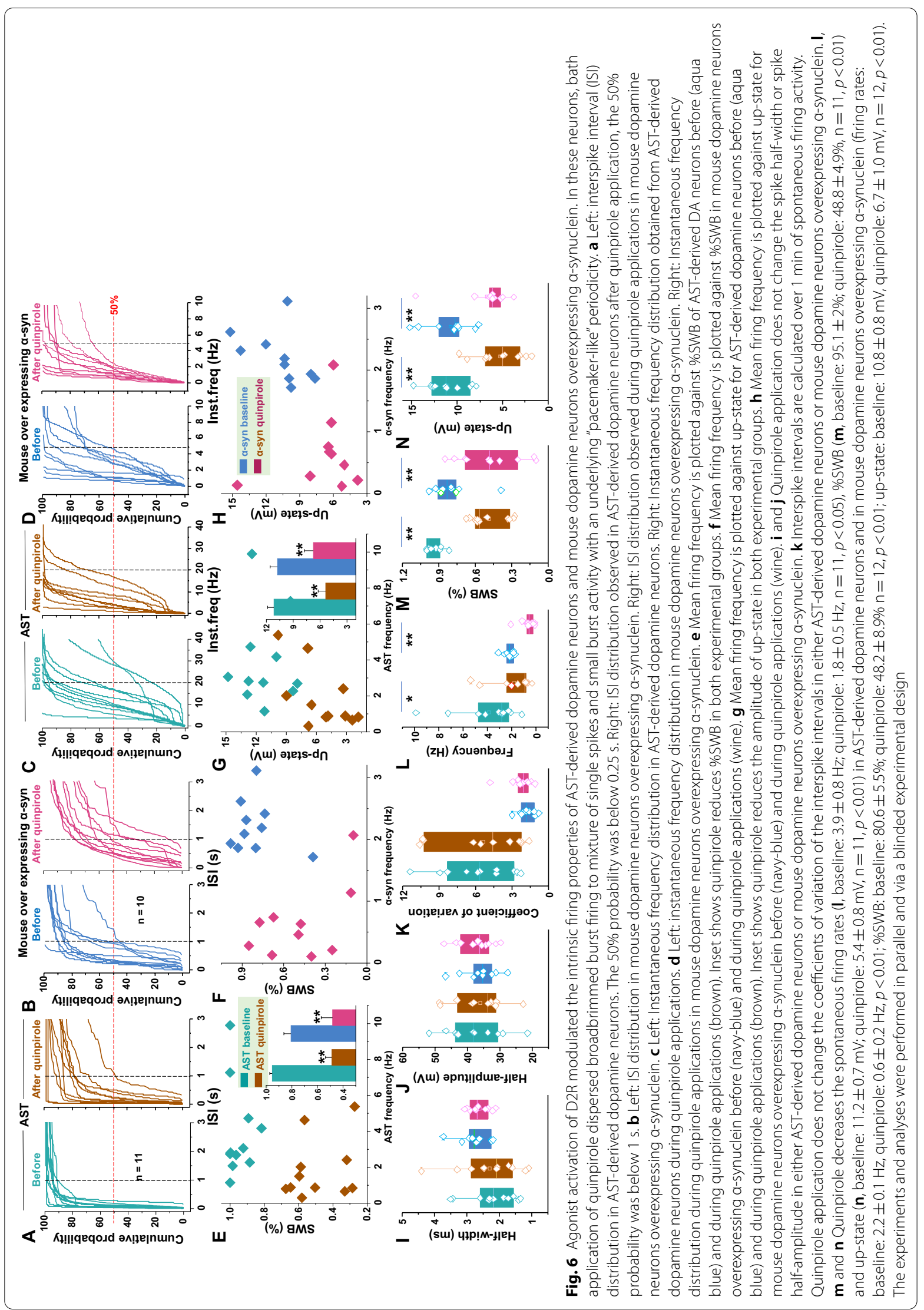


$\mathrm{m})$. Quinpirole reduced the firing frequency from $3.9 \pm 0.8 \mathrm{~Hz}$ to $1.8 \pm 0.5 \mathrm{~Hz}$ in AST-derived dopamine neurons and from $2.2 \pm 0.1 \mathrm{~Hz}$ to $0.6 \pm 0.2 \mathrm{~Hz}$ in mouse dopamine neurons overexpressing $\alpha$-synuclein (Fig. 6l). Quinpirole suppressed the up-state amplitude in both AST-derived dopamine neurons (from $11.2 \pm 0.7 \mathrm{mV}$ to $5.4 \pm 0.8 \mathrm{mV}, p<0.001, \mathrm{n}=11$, Fig. $6 \mathrm{~g}$ inset) and in mouse dopamine neurons overexpressing $\alpha$-synuclein (from $10.8 \pm 0.8 \mathrm{mV}$ to $6.7 \pm 1.0 \mathrm{mV}, p=0.003, \mathrm{n}=12$, Fig. 6h, n). Notably, quinpirole did not affect action potential width, amplitude or coefficient of variation of firing frequency in either AST-derived dopamine neurons or mouse dopamine neurons overexpressing $\alpha$-synuclein. Taken together, these results support the interpretation that while increases in $\alpha$-synuclein in human-like or mouse dopamine neurons alter neuronal firing behavior, agonist activation of D2R reinstates innate neuronal activity. Furthermore, these data suggest that D2R functional availability may be decreased at baseline in dopamine neurons overexpressing $\alpha$-synuclein.

\section{Dopamine neurons overexpressing a-synuclein exhibited} low sensitivity to inhibition of dopamine $\mathrm{D} 2$ receptors Next, we reasoned if the functional availability of D2R is limited in the AST-derived dopamine neurons and in mouse dopamine neurons overexpressing $\alpha$-synuclein, then antagonism of D2R would produce little to no effect on their intrinsic firing behaviors included firing frequency, the \%SWB and ISI distributions. As expected, although sulpiride, a D2R antagonist, mildly increased up-state and the size of broadbrimmed firing burst in both of AST (Fig. 7a1 brown) and mouse dopamine neuron overexpressing $\alpha$-synuclein (Fig. 7a2 wine), there was no difference in firing frequency, half-width, half-amplitude (Fig. 7a3, b3), phase plot (Fig. 7b, c) and ISI distribution (Fig. 7d).

Contrary to the effect of $\mathrm{D} 2 \mathrm{R}$ agonist, inhibition of D2R had no effect on the distribution of individual ISI or instantaneous frequency in either AST-derived dopamine neurons (Fig. 8a for ISI, 8c for instantaneous frequency) or mouse dopamine neurons overexpressing $\alpha$-synuclein (Fig. 8B for ISI, 8d for instantaneous

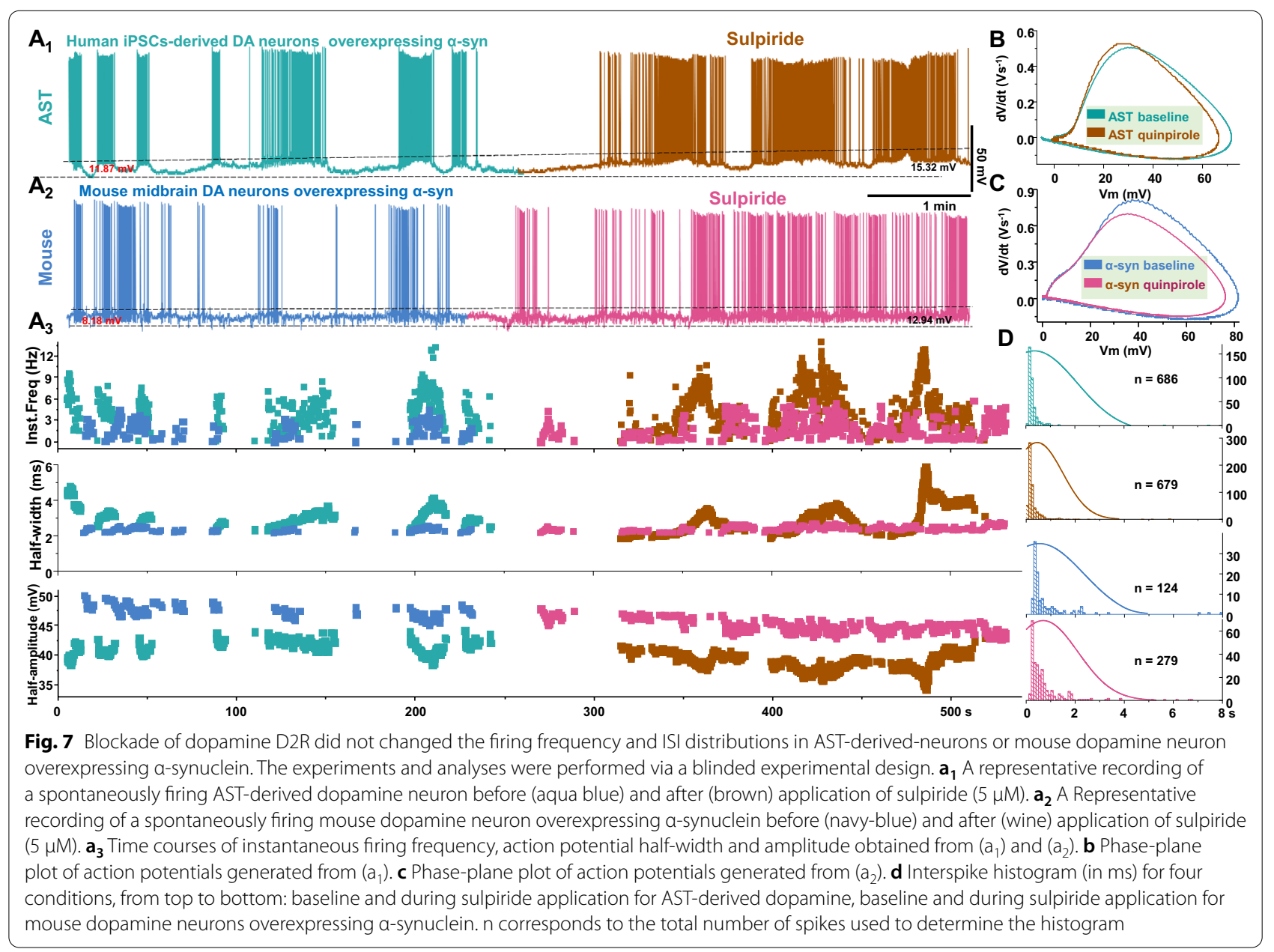




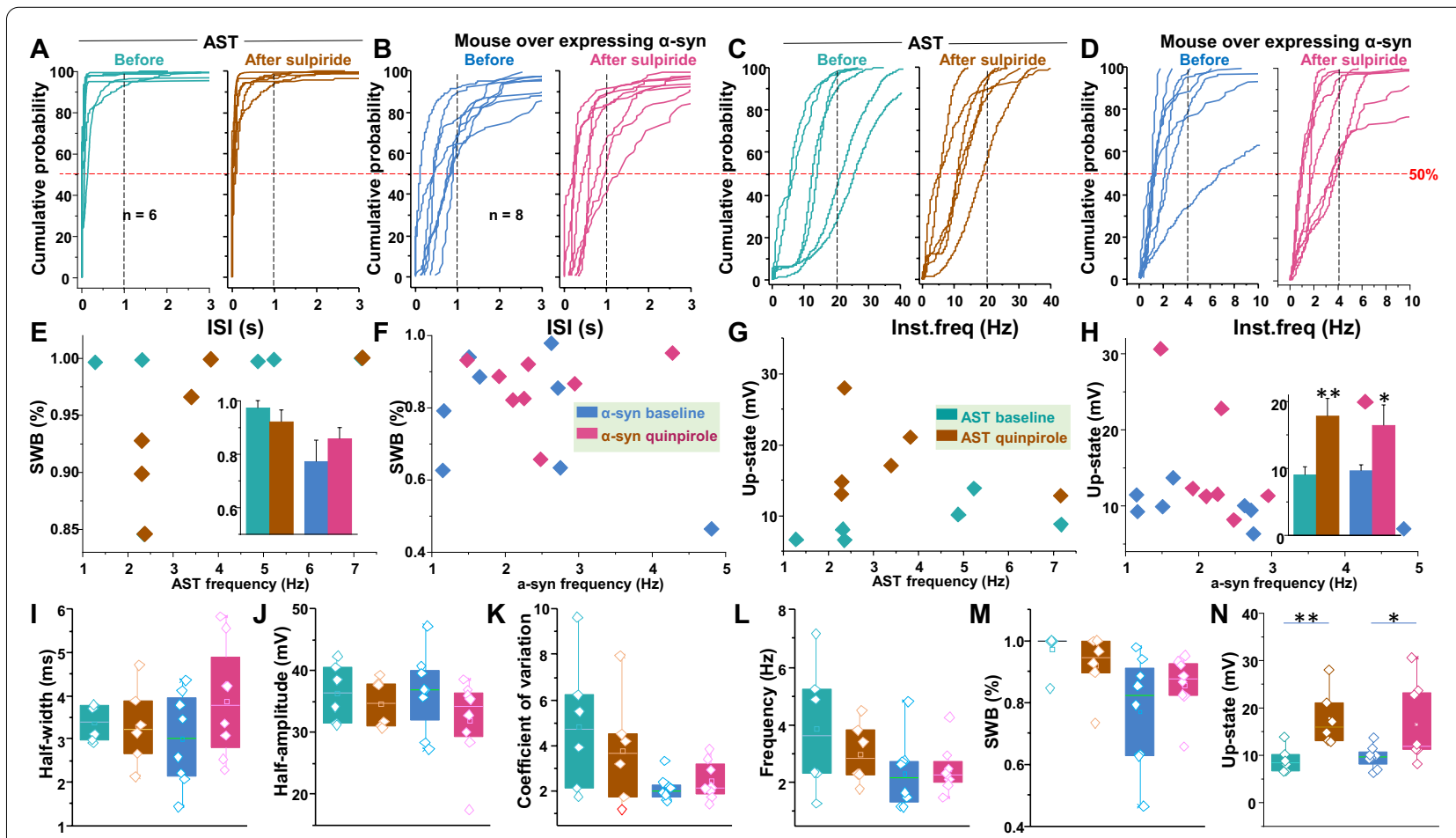

Fig. 8 Blockade of D2R did not affected the intrinsic firing behaviors in the AST-derive dopamine neurons, or mouse dopamine neuron overexpressing a-synuclein. a Left: interspike interval (ISI) distribution observed in AST-derived dopamine neurons. The 50\% probability was below 0.25 s. Right: ISI distribution observed in AST-derived dopamine neurons after sulpiride applications $(5 \mu \mathrm{M})$, the $50 \%$ probability was below $0.25 \mathrm{~s}$. b Left: ISI distribution observed in mouse dopamine neurons overexpressing a-synuclein. Right: ISI distribution observed in mouse dopamine neurons overexpressing a-synuclein during sulpiride applications (5 $\mu \mathrm{M})$. c Left: Instantaneous frequency distribution obtained from AST-derived dopamine neurons. Right: Instantaneous frequency distribution obtained from AST-derived dopamine neurons during sulpiride applications. $\mathbf{d}$ Left: Instantaneous frequency distribution obtained from mouse dopamine neurons overexpressing a-synuclein. Right: Instantaneous frequency distribution obtained from mouse dopamine neurons overexpressing a-synuclein during sulpiride applications. e Mean firing frequency is plotted against \%SWB for the AST-derived dopamine neurons before (aqua blue) and during sulpiride applications (brown). Inset shows sulpiride did not affect \%SWB in either AST-derived dopamine neurons or mouse dopamine neurons overexpressing a-synuclein. f Mean firing frequency plotted against \%SWB for mouse dopamine neurons overexpressing a-synuclein before (navy-blue) and during sulpiride applications (wine). g Mean firing frequency is plotted against up-state for the AST-derived dopamine neurons before (aqua blue) and during sulpiride applications (brown). $\mathbf{h}$ Mean firing frequency is plotted against up-state for mouse dopamine neurons overexpressing a-synuclein before (navy-blue) and during sulpiride applications (wine). Inset shows sulpiride significantly increased up-state in both AST-derived dopamine neurons and mouse dopamine neurons overexpressing a-synuclein. $\mathbf{i}$ and $\mathbf{j}$ Sulpiride did not affect the spike half-width the spike half-amplitude in either experimental groups (AST-derived dopamine neurons or mouse dopamine neurons overexpressing a-synuclein). $\mathbf{k}, \mathbf{I}, \mathbf{m}$, and $\mathbf{n}$ Sulpiride application did not produce additional change in: coefficient of variation of the interspike intervals ( $\mathbf{k}, p>0.05$; one-way ANOVA followed by Tukey's test, $n=6$ for AST, $n=8$ for mouse), spontaneous firing rates ( $\mathbf{l}, p>0.05$; one-way ANOVA followed by Tukey's test, $\mathrm{n}=6$ for AST, $\mathrm{n}=8$ for mouse), and \%SWB ( $\mathbf{m}, p>0.05$; one-way ANOVA followed by Tukey's test, $n=6$ for AST, $n=8$ for mouse), but increased up-state $(\mathbf{n}, p<0.05$; one-way ANOVA followed by Tukey's test, $n=6$ for AST, $n=8$ for mouse) in either experimental groups

frequency). No group differences were observed in either firing frequency (Fig. 8l) and \%SWB (Fig. 8e, $\mathrm{m})$ after sulpiride treatment, even though it mildly increased the magnitude of the up-state in both of AST-derived dopamine neurons (Fig. 8g, n) and mouse dopamine neurons overexpressing $\alpha$-synuclein (Fig. $8 \mathrm{~h}$, $\mathrm{n})$. Moreover, inhibition of D2R did not produce additional reduction in the half-width (Fig. 8i), decrease the half-amplitude (Fig. 8j), or increase in the coefficient of variation of the ISI in the AST-derived or mouse dopamine neurons overexpressing $\alpha$-synuclein (Fig. 8k).
These data suggest that $\alpha$-synuclein decreases the functional availability of D2R in the AST-derived dopamine neurons and mouse dopamine neurons overexpressing $\alpha$-synuclein.

\section{NAS- and AST-derived dopamine neurons express D2 receptor and GIRK channels known to regulate their firing activity}

In addition to the canonical markers of dopamine transporter and tyrosine hydroxylase, dopamine neurons express presynaptic D2 receptors and G protein-coupled 
inwardly rectifying potassium channel (GIRK) that selfregulate dopamine neuron activity [40, 59]. Importantly, GIRK2 expression within dopamine neurons is widely believed to distinguish the substantia nigra type dopamine neuron from the ventral tegmental area type dopamine neuron [38, 54, 67, 89, 125, 132]. Since our data suggest that $\mathrm{D} 2 \mathrm{R}$ activation rescues $\alpha$-synuclein-induced dysregulation of firing activity, we tested whether or not direct activation of GIRK would produce the same effect. Bath application of ML297 (10 $\mu \mathrm{M})$, a GIRK channel activator, decreased the size of bursts, increased the ISI, and suppressed the upstate of AST-derived dopamine neurons, but only co-application of ML297 and quinpirole converted the AST firing behavior back to NAS-like firing (Additional file 1: Fig. S3). Furthermore, inhibition of GIRK channels or combined inhibition of GIRK channels and D2Rs worsens the increased up-state and firing frequency in the AST-derived dopamine neurons (Additional file 1: Fig. S4). Taken together, these data support the hypothesis that the D2R-GIRK pathway is disrupted and contributes to the abnormal firing activity of ASTderived dopamine neurons.

Because our electrophysiological data pinpointed the D2R-GIRK pathway being of particular interest, we employed RNA sequencing to identify putative transcripts involved in D2R signaling. Overall, we found many of the elements downstream of D2R were increased, including the GBy subunit, which regulates GIRK channel activity (Fig. 9a). Additionally, many of the affected pathways downstream from D2R converged on processes such as neurotransmitter uptake and synaptic transmission. We next examined the GIRK network and found that transcripts for many of the potassium channels related to GIRK complexes were upregulated in the AST-derived neurons, resulting in an overall decrease in GIRK1/2/4 complexes (Fig. 9b). The increase in the D2R pathway and increase in the GIRK network suggest a possible compensatory attempt due to loss of functional availability of the D2R autoinhibitory pathway.
Taking a more global approach, we found 1512 differentially expressed genes between the NAS and the AST-dervied dopamine neurons (Fig. 9c). 916 genes were decreased in the AST-derived dopamine neurons. Some of the most significantly regulated genes involved synaptic maintenance and cytoskeletal organization, consistent with the hypothesized role of $\alpha$-synuclein in synaptic structure (Additional file 2: Data). Gene Set Enrichment Analysis (GSEA) revealed that one of the most regulated gene sets was the Dopamine/Gs Expression Targets (Fig. 9d), further supporting our functional data that dopamine receptor signaling is involved in AST-derived neuron dysfunction. Additional gene sets that were differentially regulated in the AST versus NAS groups included DRD1/5 expression targets and DRD3 $\rightarrow$ Dopamine Uptake (Additional file 3: Table S1). Overall, our transcriptomic analyses suggest that dopamine signaling is severely dysregulated in the AST-derived dopamine neurons and support the notion that the D2R-GIRK pathway may be disrupted.

We then sought to validate our findings at the protein level using double blinded and parallel immunostaining assays from three independent rounds of differentiation. We found that AST- and NAS-derived dopamine neurons express D2R and GIRK. Representative immunolabeling of D2R and GIRK in NAS- and AST-derived dopamine neurons are shown in Fig. 9e. There is lower a.u. $/ \mu \mathrm{m}^{2}$ immunolabeling for $\mathrm{D} 2 \mathrm{R}$ in the AST-derived dopamine neurons (Fig. 9f, $1.6 \pm 0.04$ a.u. $/ \mu^{2}{ }^{2}, \mathrm{n}=125$ ) compared to NAS-derived dopamine neurons $(3.0 \pm 0.1$ a.u. $/ \mu \mathrm{m}^{2}, \mathrm{n}=136$, from three independent rounds of differentiation). Similarly, compared to NAS-derived dopamine neurons $\left(2.8 \pm 0.09\right.$ a.u. $\left./ \mu \mathrm{m}^{2}, \mathrm{n}=126\right)$, ASTderived dopamine neurons show significantly lower a.u. $/ \mu \mathrm{m}^{2}$ immunolabeling for GIRK $(1.3 \pm 0.04$ a.u. / $\mu \mathrm{m}^{2}, \mathrm{n}=133$, Fig. 9f). As described in literature derived from the Lovinger's lab and other groups, the frequently used D2R and GIRK antibodies [27] are raised against the intracellular domain of these membrane proteins,

\footnotetext{
(See figure on next page.)

Fig. 9 The transcriptome network and immunostaining for D2R and GIRK channels. a D2R pathway showed overall upregulation in AST-derived dopamine neurons with most elements in the D2R signaling cascade, such as G $\beta \gamma$, increased in relative expression (red). Green indicates downregulation and gray indicates no change. Key to abbreviations provided in Additional file 3: Table S1. b A transcriptome network for GIRK in AST-derived neurons. Overall, there was an increase in this network. Red indicates that the transcript is increased in abundance and blue indicates that transcript is decreased in relative abundance compared to NAS. Gray indicates an entity or gene that was not measured or detected in derived neurons. Abbreviations are provided in B. c Analysis of bulk RNA sequencing of AST-derived dopamine neurons $(n=3)$ and NAS-derived dopamine neurons $(n=3)$ revealed 1512 differetially expressed genes with 916 decreased in AST-dervied dopamine neurons (log2(Fold change) $<-1$, $p<0.05$ ) and 596 increased in AST-derived dopamine neurons (log2(Fold change $>1, p<0.05$ ). $\mathbf{d}$ Gene set enrichment analysis (GSEA) depicted as a volcano plot revealed genes associated with dopamine/Gs signaling were upregulated in AST-derived vs NAS-derived dopamine neurons (Median fold change > 1.5, $p<0.05)$. e Immunostaining for GIRK2 channel ( $\left.K_{i r} 3.2\right)$ and D2R after 5 months differentiation of NAS and AST. $\mathbf{f}$ top. Parallel immunostaining via a blinded experimental design, revealed a lower $\mathrm{K}_{\mathrm{i}} 3.2$ expression in AST-derived neurons than in NAS-derived neurons $\left(t_{257}=14.01, p<0.001\right.$, two-tailed Student's $t$ tests, $\left.n: N A S=126, A S T=133\right)$. Bottom. Parallel immunostaining showed a reduced D2R expression in the AST-derived neurons compared with NAS-derived neurons ( $\mathrm{t}_{259}=13.59, p<0.001$, two-tailed Student's $\mathrm{t}$ tests, $\mathrm{n}$ : NAS $=136, \mathrm{AST}=125$ )
} 


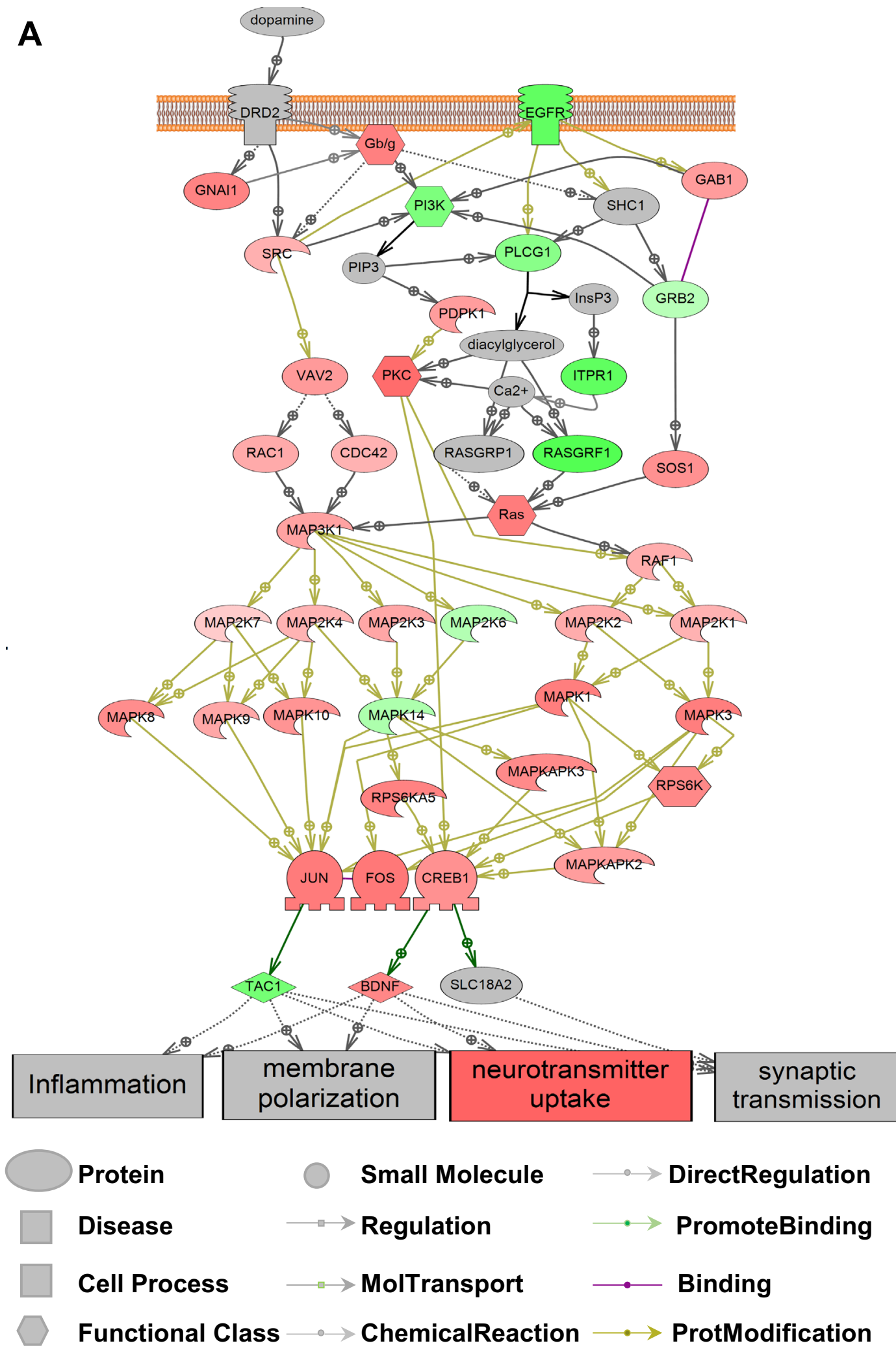




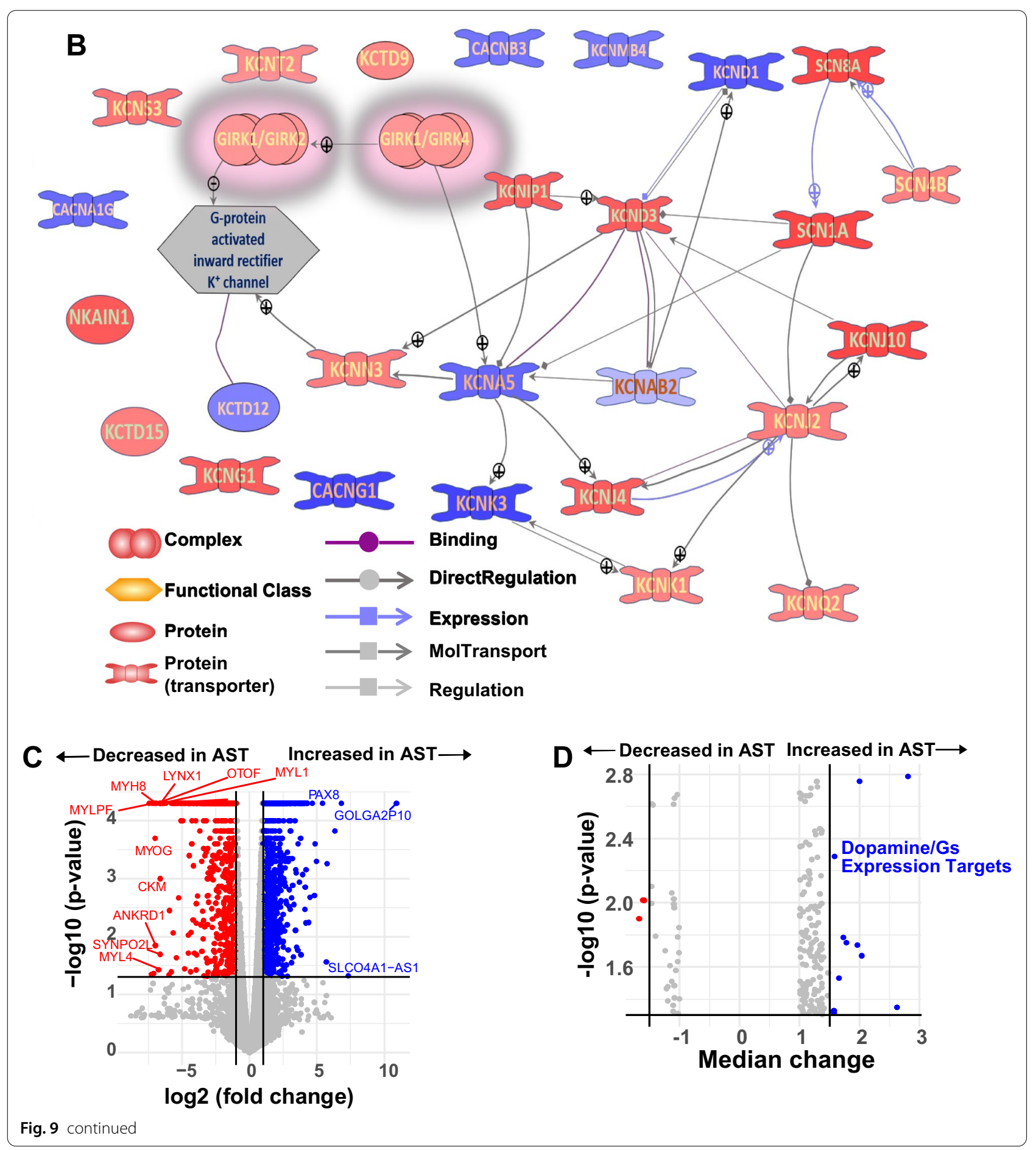




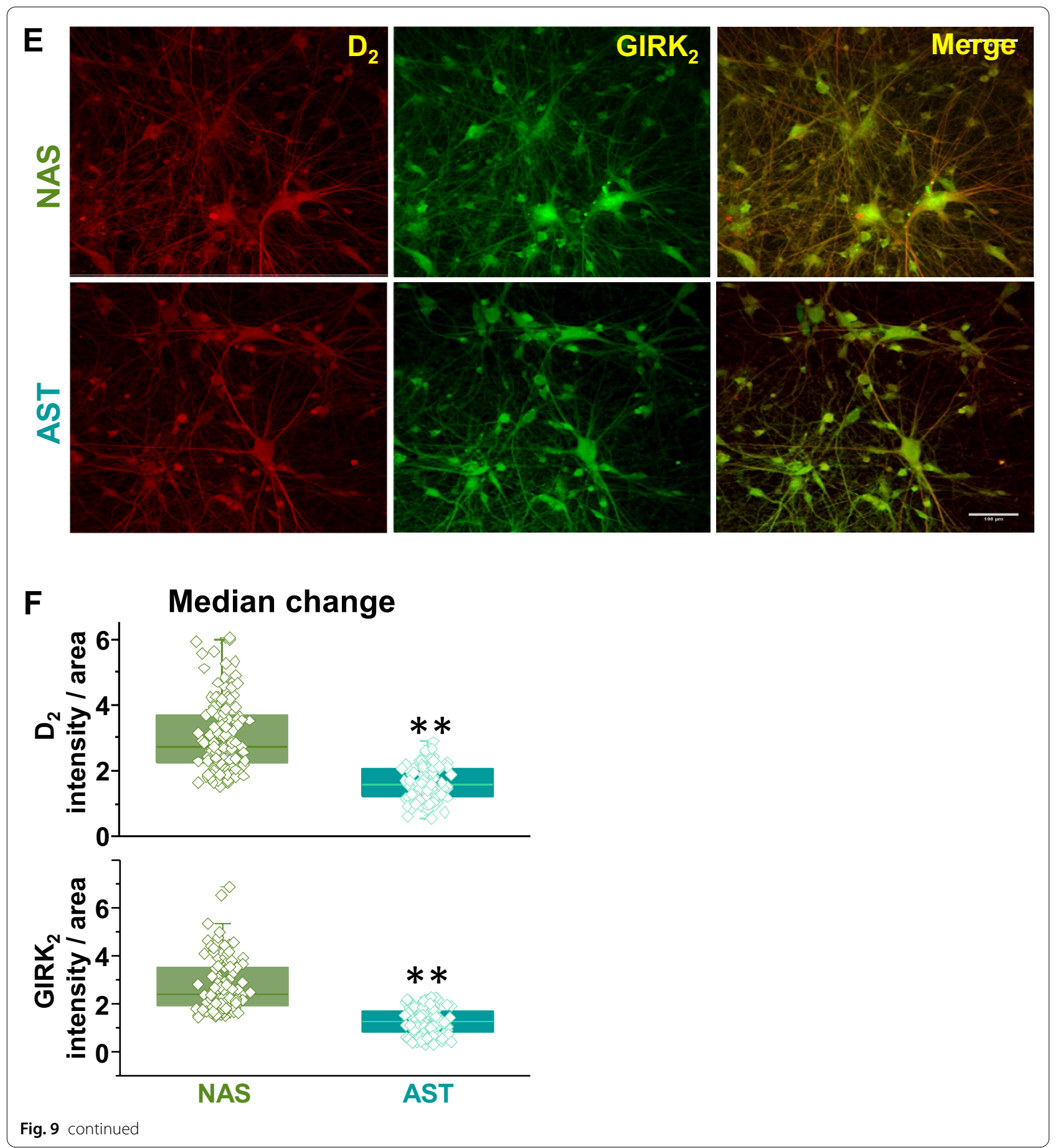

therefore, the immunostaining data shown here are limited to identifying the total (cytoplasmic + membrane) D2R or GIRK levels. However, taken in the context of our earlier findings (Figs. 5, 6, 7, 8), these data support the overall notion that the D2R-GIRK pathway is functionally disrupted by increases in $\alpha$-synuclein and that it represents a pharmacological target to restore normal neuronal activity. 
Single-neuron recordings show AST-derived dopamine neurons are less sensitive to D2R agonist and GIRK channel enhancer

In order to test our hypothesis that the D2R-GIRK pathway is functionally disrupted in AST-derived dopamine neurons, we performed complementary single-neuron recordings of D2R-mediated inward current. We measured D2R-mediated inward currents in the NAS- or AST- derived dopamine neurons after a brief (100 ms duration) focal application of quinpirole $(5 \mu \mathrm{M}, 100 \mathrm{~ms}$ duration, $10 \mathrm{psi}$ pressure, $50-100 \mu \mathrm{m}$ application distance). The membrane voltage was held at $-60 \mathrm{mV}$ in the voltage-clamp configuration. The rapid application of quinpirole induced an inward current in NAS- or ASTderived neurons (Fig. 10a). The activation of D2R in the AST-derived dopamine neurons produced a significantly smaller inward current, compared with the inward current measured in the NAS-derived dopamine neurons (Fig. 10a, c, $p<0.05$, Kolmogorov-Smirnov test). These data are consistent with our RNA sequencing data and the interpretation that the D2R-GIRK autoinhibitory pathway is functionally uncoupled, leading to decreased D2R-induced inward currents.

It has been shown that D2R activation increases GIRK conductance [12]. Therefore, we investigated whether the same stimulation protocol can generate GIRK-mediated current. We found a rapid and focal (100 ms duration, 10 psi pressure, $50-100 \mu \mathrm{m}$ application distance) applications of $5 \mu \mathrm{M}$ ML297, a GIRK activator, produced an inward current with spike-like shape in NAS-derived dopamine neurons (Fig. 10b). Similar to the D2R-medited currents, the size of ML297-induced GIRK-mediated current in AST-derived dopamine neurons was significantly smaller than those from NAS-derived neurons (Fig. 10b, d, $p<0.05$, Kolmogorov-Smirnov test). Therefore, these data indicate that GIRK function is also decreased in AST-derived dopamine neurons, independent of D2R signaling. These findings collectively support the interpretation that $\alpha$-synuclein overexpression decreases activities of both D2R signaling and GIRK channels.

\section{AST-derived dopamine neurons exhibited lower dopamine release}

The depolarization-induced dopamine release is one of the hallmarks of dopamine transmission [92]. The activity dependent properties of dopamine neurons allow them to optimize the release of dopamine in their terminal fields. Thus far, we have shown that both ASTand NAS-derived dopamine neurons have pacemaker activity, albeit with different patterns, that theoretically should lead to dopamine release. To measure depolarization-induced dopamine release we used $\mathrm{GRAB}_{\mathrm{DA} 4.4}$
(G protein-coupled receptor [GPCR]-activation-based) sensor-expressing HEK293 cells to measure extracellular dopamine levels. $\mathrm{GRAB}_{\mathrm{DA} 4.4}$ is a genetically encoded fluorescent dopamine sensor, engineered by coupling a conformationally-sensitive circular-permutated EGFP (cpEGFP) to D2 receptor. In $\mathrm{GRAB}_{\mathrm{DA} 44^{-}}$-expressing HEK293 cells (sniffer cells), dopamine binding to the sensor induces a conformational change which results in a robust increase in fluorescence signal in a concentration-dependent manner (Additional file 1: Fig. S5). We employed this approach to measure depolarizationinduced changes in GRAB ${ }_{\mathrm{DA} 4.4}$ fluorescence signal when the $\mathrm{GRAB}_{\mathrm{DA} 4.4}$-expressing HEK293 cells were co-cultured with the NAS- or AST-derived dopamine neurons (Fig. 11). Notably, since the sensor is D2R-based, we co-

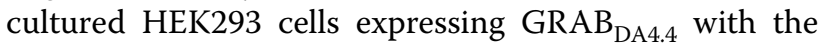
AST- and NAS-derived dopamine neurons to the possible confounder of differential D2R expression between the conditions. Via the cell-attached experimental configuration, a NAS - or AST-derived dopamine neuron was stimulated using a brief (10-ms) episodic (once every $1 \mathrm{~s}$ ) depolarizing current (100 pA) pulse (Fig. 11b). The florescence intensity of sniffer cells $\left(\mathrm{GRAB}_{\mathrm{DA} 4.4^{-}}\right.$-expressing HEK293 cells) rapidly increased following electrical stimulations, indirectly measuring dopamine release from the neuron (Fig. 11c). Employing an identical electrical stimulation protocol (10 ms, once every $1 \mathrm{~s})$, the average florescence intensity of sniffer cells co-cultured with the AST-derived dopamine neuron was lower than those co-cultured with the NAS-derived dopamine neuron (Fig. 11c, $p<0.05$, Kolmogorov-Smirnov test). Taken in the context of the decreases in TH, DAT, and Nrr1 transcripts in AST-derived dopamine neurons (Fig. 2b), our data collectively indicate that $\alpha$-synuclein induces an increase in burst firing coupled to decrease in dopamine release per action potential.

\section{AST-derived dopamine neurons exhibit reduced arborization and larger soma area}

$\alpha$-synuclein has multiple characterized functions in neurons, such as sensing membrane curvature. It can also induce extensive membrane reshaping and membrane re-modelling [39, 95]. Morphological restructuring and decreased neuronal complexity have also been a hallmark of neuronal degeneration $[17,30,81]$. To examine whether increased $\alpha$-synuclein affects overall neuronal arborization we measured soma area, neuronal perimeter, and neurite length in the AST- and NAS-derived human dopamine neurons. Morphological analyses of differentiated neurons revealed that AST-derived dopamine neurons exhibited larger soma area and perimeter than NAS-derived dopamine neurons (Fig. 12b, soma area, $712.3 \pm 22.4 \mu \mathrm{m}^{2}$ in NAS, vs. $1082.4 \pm 29.7 \mu \mathrm{m}^{2}$ in AST, 


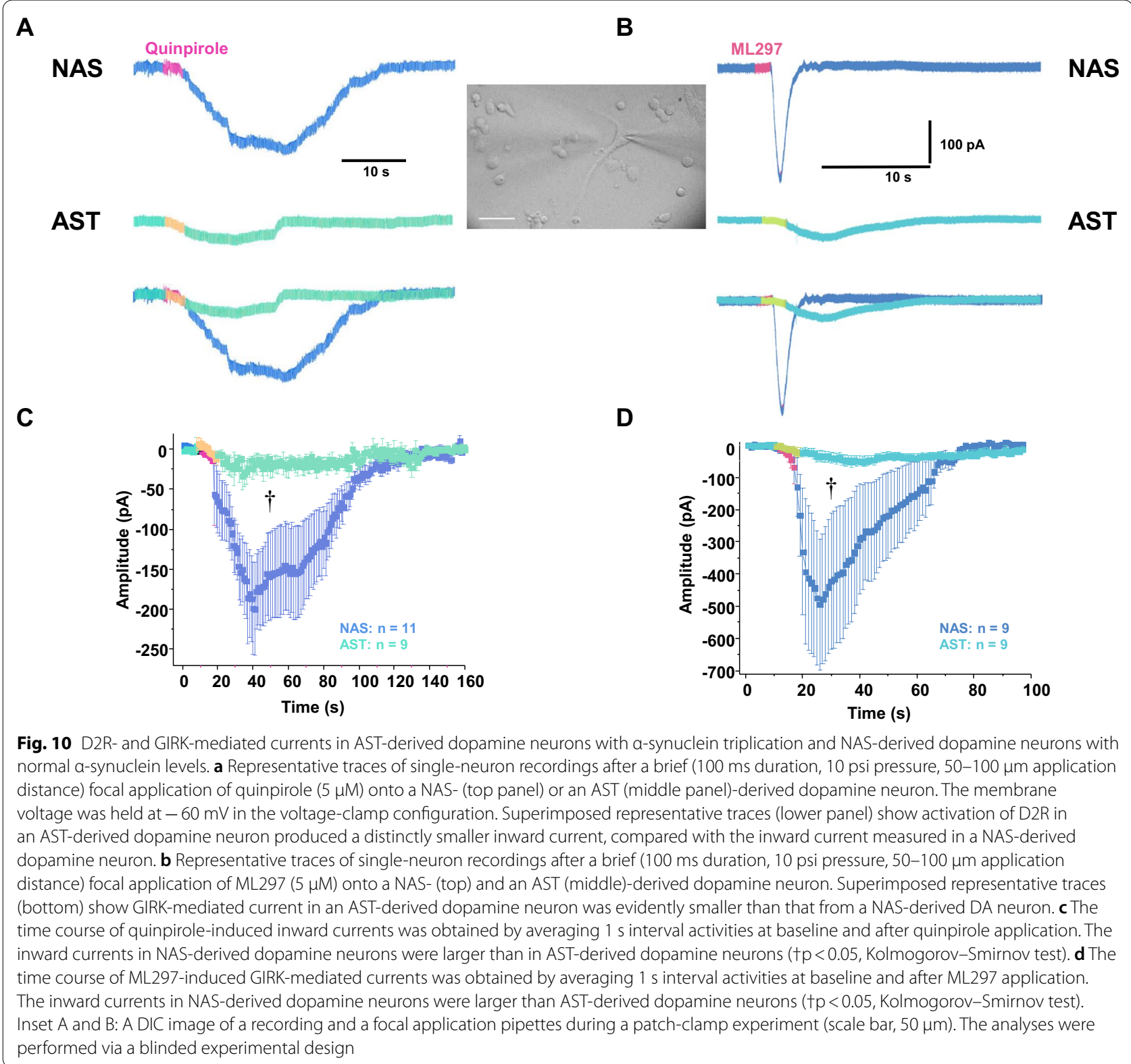

$p<0.001, \mathrm{n}=159-174$, from three independent rounds of differentiation. The perimeter comparison is shown in Fig. 12c, NAS: $111.3 \pm 1.8 \mu \mathrm{m}$ vs. AST: $161.4 \pm 2.7 \mu \mathrm{m}$, $\mathrm{p}<0.001, \mathrm{n}=159-174$, from three independent rounds of differentiation). AST-derived dopamine neurons also had shorter neurites (Fig. 12d, NAS: $187.2 \pm 7.5 \mu \mathrm{m}$ vs. AST: $126.7 \pm 3.7 \mu \mathrm{m}, p<0.001, \mathrm{n}=144$, from three independent rounds of differentiation). The loss of neuronal complexity found in AST-derived dopamine neurons is consistent with post-mortem histopathological analysis in PD patients [65] suggesting decreased neuronal complexity and dendritic arborization precede neuronal death $[17,30,81]$. Thus, $\alpha$-synuclein induces dysfunctional neuronal activity coupled to morphologic changes consistent with the events leading to degeneration.

\section{Discussion}

In patients with $\alpha$-synuclein triplication, the mechanisms culminating in progressive loss of dopamine neurons prior to clinical manifestation of Parkinson's disease (PD) remain elusive. Human iPSCs-derived dopamine neurons from patients with inherited pathologies such as PD provide a clinically relevant model system to study 


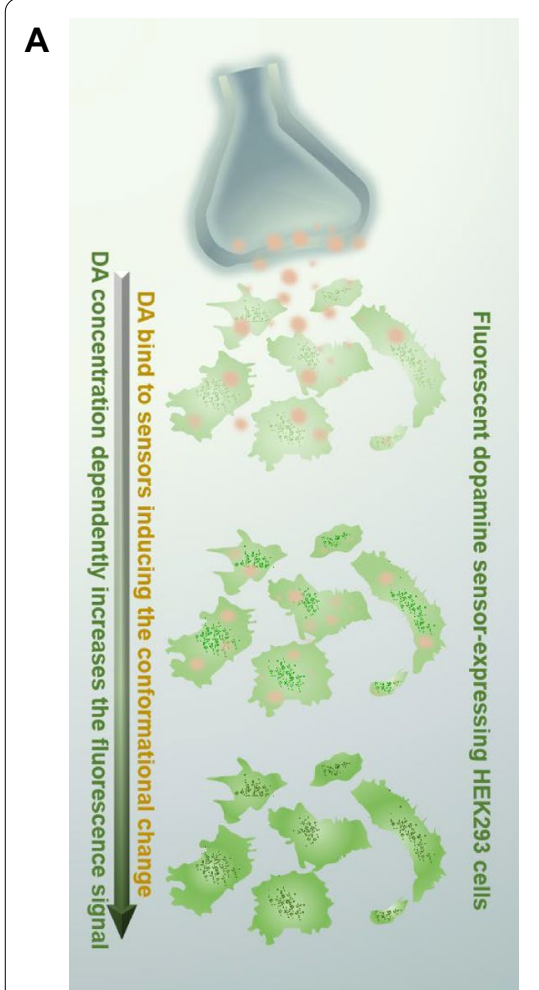

B
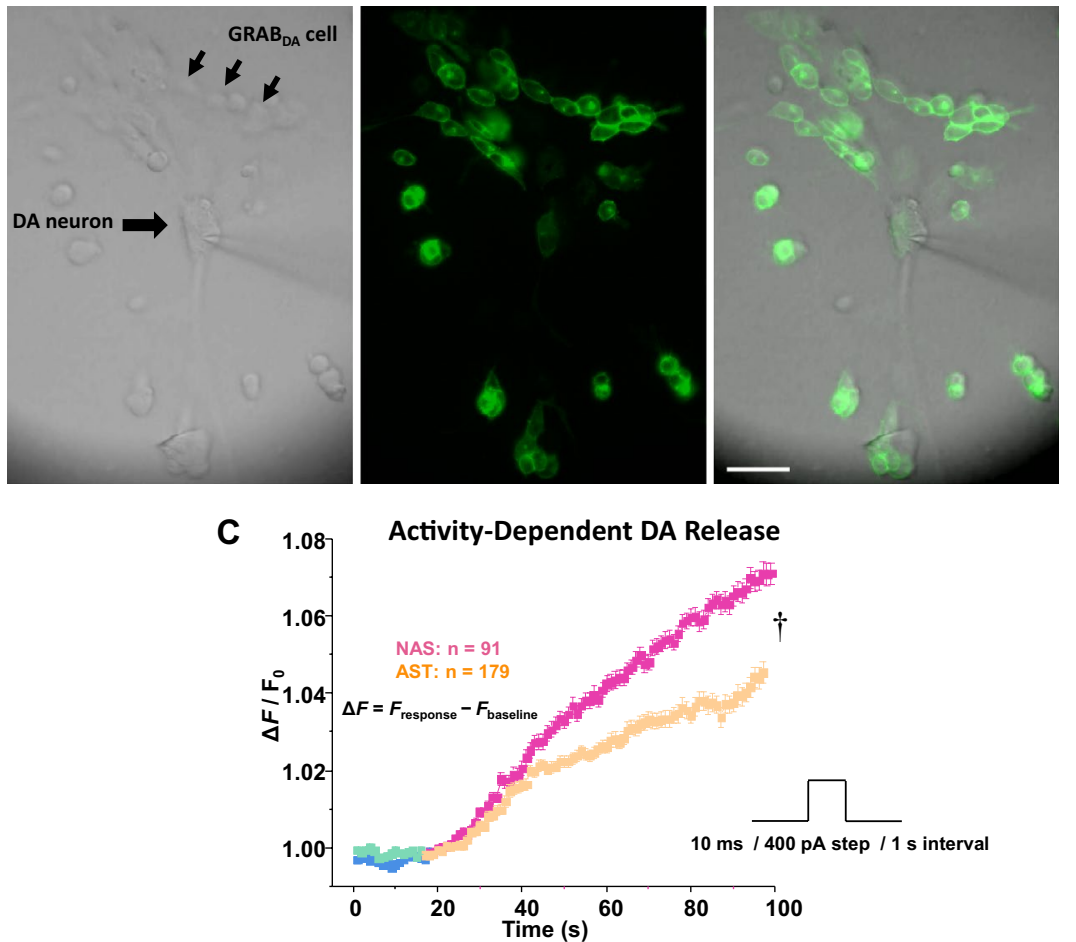

Fig. 11 The depolarization-induced dopamine release is lower in AST-derived dopamine neurons. a Cartoon shows the experimental design for the detection of dopamine released from AST- or NAS-derived dopamine neurons. $\mathbf{b}$ The representative DIC image (left) shows: the stimulating electrode in cell-attached configuration, the neuron and sniffer cells (GRABDA4.4-expressing HEK293 cells) (middle) co-cultured with the neurons $24 \mathrm{~h}$ before experiments. The right panel shows the merged image (scale bar, $50 \mu \mathrm{m}$ ). c Via the cell-attached experimental configuration, a NAS- or AST-derived dopamine neuron was stimulated using a brief (10-ms) episodic (once every $1 \mathrm{~s}$ ) depolarizing current (100 pA) pulse. The florescence intensity of sniffer cells rapidly increased following electrical stimulations, indirectly measuring fold change $\left(\Delta F / F_{0}\right)$ in dopamine release from the neuron. The fluorescence signals were normalized to the averaged intensity of first $60 \mathrm{~s}$ for each experimental condition. The average florescence intensity of sniffer cells co-cultured with the AST-derived dopamine neuron was lower than those co-cultured with the NAS-derived dopamine neuron $(t p<0.05$, Kolmogorov-Smirnov test). The experiments and analyses are performed via a blinded experimental design

pathophysiological manifestation of earlier development of PD prior to neuronal demise. The iPSC-derived dopamine neuron model system is applicable in biomedicine, specifically in the development of patient specific therapeutic strategies. In this study, we employed a previously used differentiation protocol to generate human-like dopamine neurons from a PD patient with $\alpha$-synuclein triplication (AST) and an unaffected firstdegree relative (NAS), serving as a control with a similar genetic background to minimize phenotypic differences. We found after four weeks of neuronal differentiation, both AST- and NAS-derived cells express TH, DAT and $\alpha$-synuclein. However, these neuronal-like structures are silent; they do not exhibit spontaneous firing activity, a hallmark of dopaminergic neurons. We determined after a longer differentiation period of 150 days, both ASTand NAS-derived dopamine neurons not only expressed the canonical markers of dopaminergic neurons (Figs. 1, 2), but also exhibited spontaneous firing activity (Figs. 3,
4). Our functional analyses revealed striking observations of increased broadbrimmed spontaneous firing activity in the AST-derived dopamine neurons that is due to reduced D2R-mediated autoinhibition on these neurons. Our approach enables large-scale studies of an early pathophysiological manifestation of increased $\alpha$-synuclein in dopamine neurons prior neuronal demise and provides a possible pharmacological target to alleviate neuronal dysfunction.

To investigate the nature of dopamine transmission before neuronal demise, we measured the activity of human-like dopamine neurons with or without increased $\alpha$-synuclein levels, AST and NAS neurons respectively. Since the intrinsic firing behavior of cultured WT mouse dopamine neurons is well-established $[46,56,75,84]$, we compared the firing behavior of NAS-derived dopamine neurons to cultured WT mouse dopamine neurons with endogenous or overexpression of $\alpha$-synuclein. Spike frequency for dopaminergic neurons is within a wide range 


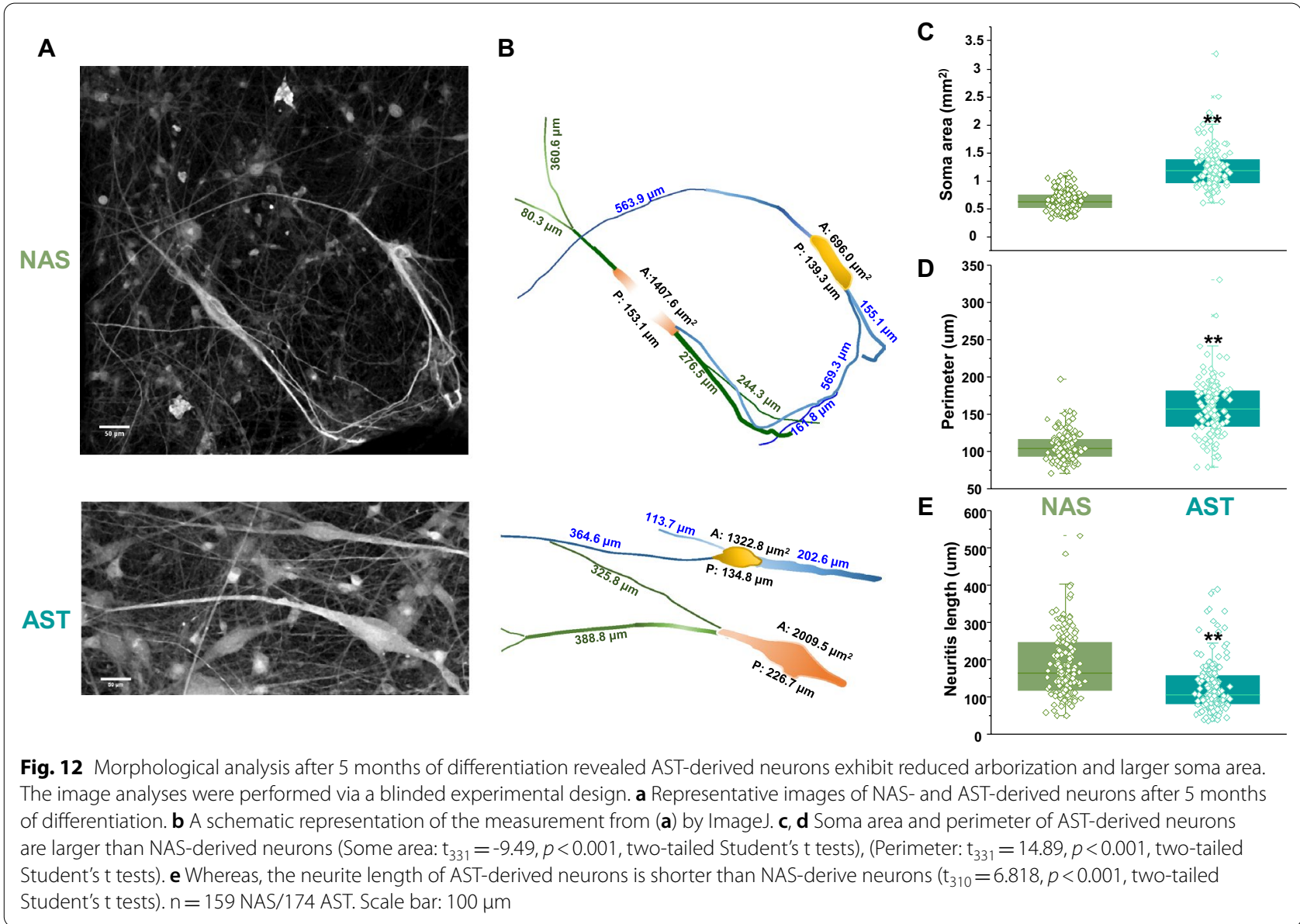

that can be as low as $0.5 \mathrm{~Hz}$ or as high as $20 \mathrm{~Hz}[12,46$, $48,52,56,66,75,76,84,108,110,124]$. Consistent with the literature, we found both NAS-derived dopamine neurons and WT mouse dopamine neurons exhibited characteristic pacemaker-like firing activity and irregular burst firing pattern of 3-8 Hz. But, unexpectedly, the AST-derived human like dopamine neurons exhibited a unique pattern of spontaneous firing activity characterized by increased broadbrimmed firing bursts with a pause between subsequent broadbrimmed bursts and a noticeable up-state, all of which support the interpretation of reduced autoinhibitory modulation in these neurons.

In dopaminergic neurons, one of the autoinhibitory mechanisms is activation of D2 receptor-induced hyperpolarizing current via an activation of G-protein-coupled inwardly rectifying potassium (GIRK) channels. D2 receptors and GIRK channels can be coimmunoprecipitated [71], suggesting a functional interaction between the two proteins. Decreased membrane D2 levels, blockade of D2 receptors, desensitization of the receptor, or reduced receptor-effector coupling can lead to increased firing activity of dopamine neurons and the occurrence of the up-state. Neurons toggle between hyperpolarized (down-state) and depolarized (up-state) resting membrane potentials. In healthy dopamine neurons the up-state is only a few millivolts from the action potential threshold, and the membrane potential fluctuations around the up-state are of higher amplitude, whereas the down-state is relatively free of noise [73]. Reduced functional availability of D2 receptors can increase the amplitude of the up-state, augment the rate of firing frequency and enhance the size of bursts. The increased frequency and bursting can reciprocally activate D2 receptors, opening GIRK channels and increasing the membrane potassium conductance, thereby inhibiting dopamine neuron firing $[12,69,102]$. This results in long pause between subsequent broadbrimmed bursts and a noticeable up-state-the same pattern we identified in our AST-derived dopamine neurons. Our whole-cell patch clamp recordings combined with pharmacological manipulations such as application of a D2 receptor agonist (Figs. 5, 6) or a GIRK channel enhancer (Additional file 1: Fig. S3) confirmed the decreased functional 
availability of D2 receptors and GIRK channel activity in the AST-derived dopamine neurons. A D2 receptor agonist or the combinational application of D2 receptor agonist and a GIRK channel enhancer reinstated the firing activity to the levels measured in human-like dopamine neurons with endogenous levels of $\alpha$-synuclein (Figs. 5, 6 and Additional file 1: Fig. S3).

If we presume a linear relationship between functional assays described above and the transcript levels in the AST-derived neurons, the results of our functional assays are consistent with altered GIRK channel transcript, but discordant with the qPCR data for D2 receptor (Fig. 2). In addition, while immunocytochemistry data show a lower signal for D2 receptor and GIRK (Fig. 9f), we are hesitant to make any assumption about lower membrane levels of these proteins. This is because the commonly used and validated antibodies for D2 and GIRK are raised against the intracellular domain of these proteins that label both membrane and intracellular D2 receptors or GIRK channels [26, 27]. Similar technical limitations apply to the single cell qPCR assay, where total transcript levels do not necessarily reflect functional D2 receptors or GIRK channels at the membrane, receptors desensitization or altered receptor-effector coupling [9, 68, 107]. The complex interactions among D2 receptor signaling, GIRK channels and other relevant ion channels becomes more apparent with RNA-seq analysis. Therefore, live cell functional assays, such as electrophysiology, combined with pharmacological manipulations may be more reliable strategies to identify early pathophysiological manifestation of neuronal dysfunction in the AST-derived dopamine neurons. Nevertheless, a comprehensive, integrative investigation at the molecular, physiological, and morphological level will yield the most complete view of dopamine neuron dysfunction.

The notion that dopamine receptors' expression or function are altered in PD has been shown frequently in both humans and in animal models of PD. Drug-naïve PD patients have been reported to have increased D2-like [72] and decreased D3-like [16] post synaptic dopamine receptors. Notably these studies were conducted in postmortem tissue or in clinically diagnosed PD patients. Our data indicate that pre-synaptic D2R dysfunction may precede neuronal demise and the subsequent alterations in post-synaptic dopamine receptors, providing an added layer of complexity to studies on prodromal PD. Corroborating the notion that pre-synaptic dopamine receptors may be affected in PD, studies in LRRK2 mutant iPSC lines and animal models have shown D2R and D3R exhibit altered expression, localization, or function compared to control condition $[18,93,104,126]$. The consistent implication of dopamine receptor dysfunction across different forms of autosomal dominant PD suggests that alteration in dopamine receptors may represent a common pathophysiological pathway preceding dopamine neurodegeneration.

The literature supports the interpretation that increased $\alpha$-synuclein in dopamine neurons lead to dysregulation of dopamine transmission. In mouse overexpressing human $\alpha$-synuclein, Lam and colleagues reported an elevated tonic extracellular dopamine concentration that precedes loss of dopaminergic neurons followed by the eventual decline in dopamine levels due to neuronal degeneration [70]. Consistent with this report, we and others have shown $\alpha$-synuclein overexpression increases extracellular dopamine levels by decreasing dopamine uptake and a five-fold increase in dopamine transporter mediated dopamine efflux [22, 116, 130, 134]. Decreased dopamine recycling leads to increased extracellular dopamine levels [45], downregulation of D2 auto-receptor activity, and increased firing activity of the neuron, but a lower amount of dopamine release per action potential, due to decreased tissue dopamine levels. Our simultaneous electrophysiology and live-cell imaging data using GRAB- $_{\text {DA4.4 }}$ revealed attenuation of dopamine release upon membrane depolarization. Therefore, it is possible that at early, premanifest stage of PD, there is a hypodopaminergic state inside the neuron, but a transient hyper-dopamine state extracellularly.

We showed that human and mouse dopaminergic neurons with normal levels of $\alpha$-synuclein fire in tonic pacemaker fashion in striking contrast to the observed burst firing modes in the presence of increased $\alpha$-synuclein (both AST-derived human-like dopamine neurons and mouse dopamine neurons overexpressing $\alpha$-synuclein). Burst firing is observed periodically in healthy dopaminergic neurons and it requires significant bioenergetic resources [10, 46, 112, 135]. To sustain persistent burst firing patterns, dopaminergic neurons must replenish vesicular storage [41], recycle and synthesize protein [14, 57], reuptake neurotransmitter, (via a secondary activate and voltage dependent mechanism) $[22,123]$ and repolarize their membrane [33]. These innate mechanisms require increased oxygen [62], glucose [118], and ATP consumption and thereby present a metabolic burden on mitochondria $[60,77,79]$. However, in a healthy state, the burst firing occurs transiently, therefore, neuronal homeostasis is maintained. The persistent bursts in $\alpha$-synuclein overexpressing neurons may lead to increased metabolic costs that can cascade to structural and functional detriments within the neuron, such as loss of neuronal complexity [86]. This interpretation is supported by recent reports showing the extensive arborization of dopaminergic neurons is linked to neuronal vulnerability [44], which is a key contributor of metabolic costs [95]. Therefore, we propose that increases in $\alpha$-synuclein induce 
persistent bursting that imposes bioenergetic constraints within the neuron, and subsequently results in size alterations, loss of key proteins, and eventual loss of dopaminergic tone as the neuron attempts to compensate. Intervening with a D2R agonist to rescue the altered firing activity may then represent a promising strategy to forestall neuronal demise.

\section{Materials and methods}

\section{iPSCs and maintenance culture}

Via a material transfer agreement between University of Florida and University of Edinberg, we received the iPSCs of a member of the Iowa kindred carrying a triplication of the SNCA locus and an unaffected member of the family without this mutation from Dr. Tilo Kunath laboratory [32].

Mitotically inactivated mouse embryonic feeders (MEFs, ThermoFisher Scientific) were seeded onto gelatin-coated tissue culture plates at a density of $2.6 \times 104$ cells per $\mathrm{cm}^{2}$ in DMEM-F12 (ThermoFisher Scientific), with $10 \%$ fetal bovine serum, $1 \mathrm{mM}$ GlutaMax, $0.1 \mathrm{mM}$ nonessential amino acids, $100 \mathrm{U} / \mathrm{ml}$ penicillin, $100 \mu \mathrm{g} /$ $\mathrm{ml}$ streptomycin. Two days after seeding, the medium was replaced with $80 \%$ knockout DMEM, 20\% knockout serum replacer, $1 \mathrm{mM}$ GlutaMax, $0.1 \mathrm{mM}$ nonessential amino acids, $100 \mathrm{U} / \mathrm{ml}$ penicillin, $100 \mu \mathrm{g} / \mathrm{ml}$ streptomycin (all above from Thermo Fisher Scientific Life Sciences, Waltham, MA), and $4 \mathrm{ng} / \mathrm{ml}$ fibroblast growth factor (FGF-basic, Peprotech, Cranbury, NJ). iPSCs (passages 30-36), were seeded onto the MEFs, and colonies were manually passaged once every 8-10 days using a fire-polished glass Pasteur pipette. Media were changed every $48 \mathrm{~h}$ and cells were maintained at $37^{\circ} \mathrm{C} / 5 \% \mathrm{CO}^{2}$.

\section{Dopamine neuron differentiation from iPSCs}

Cells were plated $\left(35 \times 103-40 \times 103\right.$ cells per $\left.\mathrm{cm}^{2}\right)$ and grown for 5 days on matrigel (Corming)-coated dishes in knockout serum replacement medium (KSR, Life Technologies, Grand Island, NY) containing Dulbecco's Modified Eagle Medium/Nutrient Mixture F-12 (DMEM/F12, Life Technologies, Grand Island, NY), 15\% knockout serum replacement, 50 nM PD173074 (Stemcell, Vancouver, Canada), 200 ng/ml Noggin (Stemcell, Vancouver, Canada), 100 nM LDN193189 (Stemcell, Vancouver, Canada), $10 \mu \mathrm{M}$ SB431542 (Tocris, Minneapolis, MN), $500 \mathrm{ng} / \mathrm{ml}$ Shh (R \& D), $2 \mu \mathrm{M}$ Purmorphamine (ReproCell, Beltsville, MD), $0.7 \mu \mathrm{M}$ CHIR99021(Peprotech, Cranbury, NJ), $10 \mu \mathrm{M}$ Y-27632 (Peprotech, Cranbury, NJ). From day 5 to day 11, KSR containing medium was replaced with N2 (Life Technologies, Grand Island, NY) medium. PD173074 and Shh were withdrawn at day 8,but added 1\% N2 and $100 \mathrm{ng} / \mathrm{ml} \mathrm{FGF8a} \mathrm{(R} \mathrm{\&} \mathrm{D).} \mathrm{On} \mathrm{day}$ 12 , media was changed to balanced neuronal medium/
B27 containing medium (B27; Life Technologies, Grand Island, NY) supplemented with CHIR (until day 13) and with $0.5 \mathrm{mM}$ DcAMP, $200 \mathrm{ng} / \mathrm{ml}$ Noggin, $100 \mathrm{nM}$ LDN193189, $10 \mu \mathrm{M}$ SB431542 for 10 days. Cells were dissociated using Accutase (Innovative Cell Technology, San Diego, CA) and replanted under high cell density conditions $\left(300 \times 103-400 \times 103\right.$ cells per $\left.\mathrm{cm}^{2}\right)$ on $12 \mathrm{~mm}$ round coverslips coated with $100 \mu \mathrm{g} / \mathrm{ml}$ poly-l-lysine and $5 \mu \mathrm{g} / \mathrm{ml}$ laminin in $35 \times 10 \mathrm{~mm}$ tissue culture Petri dishes in N2 medium supplemented with B27, $200 \mu \mathrm{M}$ L-Ascorbic acid, $20 \mathrm{ng} / \mathrm{ml}$ BDNF, $20 \mathrm{ng} / \mathrm{ml}$ GDNF, $0.5 \mathrm{mM}$ dibutyryl cAMP (all from Millipore Sigma), $1 \mathrm{ng} / \mathrm{ml}$ TGF- $\beta 3$ (R \& D). (Fig. 1).

\section{Quantitative real-time PCR}

Total RNA was extracted using a RNeasy kit (Qiagen). For each sample, $1 \mu \mathrm{g}$ of total RNA was treated for DNA contamination and reverse transcribed using the Quantitect RT kit (Qiagen). Amplified material was detected using Quantitect SYBR green probes and PCR kit (Qiagen) on a Mastercycler RealPlex2 (Eppendorf). All results were normalized to a HPRT control and are from 4 to 6 technical replicates of 2-3 independent biological samples at each data point.

\section{RNA-seq and pathway analysis in dopamine neurons differentiated from iPSCs}

RNA concentration was determined using the Qubit ${ }^{\circledR} 2.0$ Fluorometer (ThermoFisher/Invitrogen, Grand Island, NY), and RNA quality was assessed using the Agilent 2100 Bioanalyzer (Agilent Technologies, Inc.). RNA samples with a measured $28 \mathrm{~S} / 18 \mathrm{~S}>1$ and RNA integrity number $(\mathrm{RIN}) \geq 7$ were used for RNAseq library construction. RNA-seq library were constructed using the NEBNext ${ }^{\circledR}$ Ultra $^{\mathrm{TM}}$ Directional RNA Library Prep Kit for Illumina (New England Biolabs, USA) following manufacturer's recommendations. Approximately $125 \mathrm{ng}$ of total RNA was used for mRNA isolation using the NEBNext Ploy(A) mRNA Magnetic Isolation module (New England Biolabs, USA). RNA library construction was then performed with the NEBNext ${ }^{\circledR}$ Ultra ${ }^{\mathrm{TM}}$ II Directional RNA Library Prep Kit for Illumina ${ }^{\circledR}$ (New England Biolabs, catalog \#E7760) according to the manufacturer's user guide. Barcoded libraries were sized on the bioanalyzer and quantitated by QUBIT. Six individually prepared libraries ( $n=3$ for AST and $n=3$ for NST) were pooled by equimolar and sequenced by Illumina HiSeq 3000 2X100 cycles run (Illumina Inc., CA, U.S.A). RNA library construction and sequencing were performed at the Interdisciplinary Center for Biotechnology Research (ICBR) Gene Expression and Genotyping Core, University of Florida (UF). 
Reference based transcriptome analysis was conducted for the six samples. The reference genome used was GRCh38.p10 Genome Reference Consortium Human Build 38 patch release 10 (GRCh38.p10), downloaded from the Ensemble database. From a total of 152.85 million reads, 149.45 million high quality reads were used in downstream analysis. An average of $91.47 \%$ of the reads aligned to the reference genome. An average of 83,119 transcripts and 22,485 genes were expressed across all samples. All quality control data are provided in Additional file 2: Data.

The raw data generated was first assessed for quality using FastQC (Babraham Bioinformatics). Reads were pre-processed to remove the adapter sequences and removal of the low-quality bases $(<\mathrm{q} 30)$. Pre-processing of the data was done with Cutadapt [85]. An average of $97 \%$ of high-quality reads were retained for the downstream analysis. HISAT2 [63], a splice aligner program, was used to align the sequencing data to the human reference genome using the default parameters. HISAT2 is a fast and sensitive alignment program for mapping next-generation sequencing reads (both DNA and RNA) to a population of human genomes (as well as to a single reference genome). Reads were then classified into aligned reads (which align to the reference genome) and unaligned reads. Cufflinks [127] was used to estimate and calculate transcript abundance and normalized read count using Fragments Per Kilobase of transcript per Million mapped reads (or FPKM). Cuffdiff [127] was then used to identify the differentially expressed transcripts expressed as log2fold change values. Sequencing files and expression data have been deposited in Geo NCBI (accession number: GSE163344). All expression data are provided in Additional file 2: Data.

Pathway analysis was conducted in Pathway Studio 12.3 (Elsevier). Human genes were mapped to the mammalian database using the official gene Name + Alias. Gene set enrichment analysis proceeded with 1000 permutations to generate the distributions for statistical testing (permutation test). Gene sets identified as enriched in AST compared to NST were those with a $P<0.05$. All GSEA data are provided in Additional file 2: Data along with abbreviations for gene networks presented. Normalized gene expression values, and gene set enrichment data were then plotted as volcano plots using $\mathrm{R}$ statistical software.

\section{Preparation of primary mouse midbrain dopaminergic neuronal culture}

Mice were housed in the animal care facilities at the University of Florida in accordance with Institutional
Animal Care and Use Committee, under guidelines established by National Institutes of Health. Food and water were available ad libitum in the home cage. Animals were housed under standard conditions at $22-24{ }^{\circ} \mathrm{C}, 50-60 \%$ humidity, and a $12 \mathrm{~h}$ light/dark cycle. Primary mouse midbrain dopamine neuron culture was prepared as described previously $[75,76]$. Midbrain regions from P0 mice were dissected, dissociated, and plated on Poly-l-lysince- and laminin-treated coverslips. Cells were maintained at $37{ }^{\circ} \mathrm{C}$ in a $5 \% \mathrm{CO}_{2}$ humidified incubator with a culture medium consisting of Neurobasal (Life Technologies, Grand Island, NY), $0.9 \%$ L-glutamine, $2 \%$ B27 and $1 \mathrm{ng} / \mathrm{ml}$ GDNF.

\section{Electrophysiological recordings}

Whole-cell recordings: Spontaneous firing activity of midbrain dopamine neurons was examined via whole cell current clamp recordings. The neurons were continuously perfused with aCSF containing the following (in $\mathrm{mM}$ ): $126 \mathrm{NaCl}, 2.5 \mathrm{KCl}, 2 \mathrm{CaCl}_{2}, 26 \mathrm{NaHCO}_{3}$, $1.25 \mathrm{NaH}_{2} \mathrm{PO}_{4}, 2 \mathrm{MgSO}_{4}$, and 10 dextrose, equilibrated with $95 \% \mathrm{O}_{2} / 5 \% \mathrm{CO}_{2} ; \mathrm{pH}$ was adjusted to 7.4 at $37{ }^{\circ} \mathrm{C}$. Patch electrodes were fabricated from borosilicate glass (1.5 mm outer diameter; World Precision Instruments, Sarasota, FL) with the P-2000 puller (Sutter Instruments, Novato, CA). The tip resistance was in the range of 3-5 $\mathrm{M} \Omega$. The electrodes were filled with a pipette solution containing (in $\mathrm{mM}$ ): 120 potassium-gluconate, $20 \mathrm{KCl}$, $2 \mathrm{MgCl}_{2}, 10 \mathrm{HEPES}, 0.1$ EGTA, 2 ATP, and $0.25 \mathrm{GTP}$, with $\mathrm{pH}$ adjusted to 7.25 with $\mathrm{KOH}$. All experiments were performed at $37^{\circ} \mathrm{C}$. To standardize action potential (AP) recordings, neurons were held at their resting membrane potential (see below) by DC application through the recording electrode. AP was recorded if the following criteria were met: a resting membrane potential of less than $-35 \mathrm{mV}$ and an AP peak amplitude of $>60 \mathrm{mV}$. AP half-width was measured as the spike width at the half-maximal voltage using Clampfit 10 software (Axon instruments, Foster City, CA). Steady-state basal activity was recorded for 2-3 min before bath application of the drug. For experiments involving drug application. The spontaneous spike activity of midbrain dopamine neurons was obtained by averaging $1 \mathrm{~min}$ interval activities at baseline (before drug) and after 7-10 min of drug.

The series resistances were in the range of 5-10 M $\Omega$ (typically $5 \mathrm{M} \Omega$ ) and were compensated $60 \%$ on-line. Membrane potential measurements were not corrected for the liquid junction potential $(\sim 15 \mathrm{mV})$. Leak currents were subtracted using a standard $\mathrm{P} / 4$ protocol. Before seals (5 G $\Omega$ ) were made on cells, offset potentials were nulled. Capacitance subtraction was used in all recordings. 


\section{Dopamine $D_{2}$ receptor- and GIRK-mediated inward currents recording}

The transient focal application of agonists was exploited to evoke currents. A pneumatic pico-pump (PV830, WPI, Sarasota, FL) was used for quinpirole or ML 297 delivery via a pipette (3-5 M $\Omega$ ) identical to that used for patchclamp recordings. For currents generation, a glass pipette was placed within $50-100 \mu \mathrm{m}$ of the soma, 10 psi pressure and 50-100 ms duration were applied to activate the D2R or GIRK channel. Whole-cell recordings for inward currents were obtained at $-60 \mathrm{mV}$ holding potential using an internal solution described above.

\section{Immunofluorescence staining and confocal imaging}

The neurons were grown on glass coverslips as described above. The neurons were then washed with HBSS solution (Life Technologies, Grand Island, NY) and fixed with freshly prepared $3.7 \%$ paraformaldehyde (Electron Microscopy Sciences, Hatfield, PA) for $20 \mathrm{~min}$ at room temperature and washed twice with PBS solution. For immunolabeling, the cells were then permeabilized as described previously [22, 75, 94, 110]. Washes, blocking, and incubation with primary and secondary antibodies were carried out in cell collection chambers on the stage of an orbital shaker. The neurons were incubated in blocking solution containing 10\% normal goat serum (LAMPIRE Biological Laboratories, Pipersville, PA) and 0.5\% Triton X-100 in PBS (Sigma,St. Louis, MO) at room temperature for one hour. The neurons were then incubated with a solution containing primary antibody (1:1000), $0.1 \%$ Triton $\mathrm{X}-100$ and $5 \%$ normal goat serum at $4{ }^{\circ} \mathrm{C}$ overnight. On the following day, the primary antibody was removed, and cells were subjected to three $20 \mathrm{~min}$ washes prior to addition of Alexa-Fluor 488- or 647 conjugated secondary antibodies (Life Technologies, Grand Island, NY) diluted at 1:200-500 in PBS. Cells were incubated in secondary antibody for one hour in the dark, at room temperature followed by three $20 \mathrm{~min}$ washes. Coverslips were then mounted on the Superfrost Excell Microscope Slides (VWR,West Chester, PA) using Flouromount-G (SouthernBiotech, Birmingham, AL). Slides were stored in the dark at $4{ }^{\circ} \mathrm{C}$ until imaging. Confocal images were collected using a Nikon A1 laser-scanning confocal microscope. Excitation wavelengths were set at 488 and $647-\mathrm{nm}$, for the respective fluorescent markers. Images were acquired using 488-nm excitation with a 514-nm long pass filter, 647- nm excitation with a 668-nm long pass filter. Images were taken using a $20 \mathrm{X}$ or a $60 \mathrm{X}$ Nikon objective with 1.40 NA (numerical aperture).

All imaging analyses were carried out via an automated graphic plugin for the public domain image analysis software Image) (Wayne Rasband; Research Services Branch, National Institutes of Mental Health, National Institutes of Health, Bethesda MD). The morphological analysis were performed from DIC images. For RGB images, average gray value within the selection as image intensity is the sum of the gray values of all the pixels in the selection divided by the number of pixels. The mean is calculated by converting each pixel to grayscale using the formula gray $=($ red + green + blue $) / 3$. Area of selection was in square pixels or in calibrated square units $\left(\mu \mathrm{m}^{2}\right)$. The perimeter of a composite selection is calculated by decomposing it into individual selections. The Neurite Tracing is based on multiscale image processing using both first-order (edge) and second-order (ridge) filters and combining the extracted information in a cost function that is globally minimized algorithms to detect elongated image structures and determine their centerlines [88]. The images were processed using ImageJ and the NeuronJ plugin for ImageJ which highlights and traces neurites and somas [49, 101]. The trace was manually initiated and ended of each neurite, using a crosshair pointer, and map the length and shape of each neurite with a series of connected straight lines. The tracing algorithm computed the optimal path between the selected starts and end points. Soma size was measured using the "selection brush" tool on ImageJ to carefully outline the shape of the soma. Requirements for counting a projection as a dendrite included: (1) Neurons being analyzed were at least one soma away from another neuron. (2) Projections were counted as dendrites if the length were at least the diameter of the soma. Fluorescence colocalization analysis was used to determine whether two proteins associate with the same subnuclear structures or with the same plasma membrane domains. We used three of frequently used colocalization coefficients to express the intensity correlation of colocalizing objects in each component of a dual-color image (see Additional file 2: Data): (1) Pearson's correlation coefficient: The Pearson's correlation coefficient is not sensitive to differences in mean signal intensities or range, or a zero offset between the two components. The result is +1 for perfect correlation, 0 for no correlation, and -1 for perfect anti-correlation. Noise makes the value closer to 0 than it should be [97]. (2) Spearman's rank correlation coefficient: The Spearman correlation between two variables is equal to the Pearson correlation between the rank values of those two variables, while Pearson's correlation assesses linear relationships, Spearman's correlation assesses monotonic relationships (whether linear or not). If there are no repeated data values, a perfect Spearman correlation of +1 or -1 occurs when each of the variables is a perfect monotone function of the other [120]. (3) Kendall rank correlation coefficient: the Kendall correlation between two variables will be high when observations have a similar (or identical for a correlation of 1) rank (i.e., relative 
position label of the observations within the variable: 1st, 2nd, 3rd, etc.) between the two variables, and low when observations have a dissimilar (or fully different for a correlation of -1 ) rank between the two variables. Contrary to the Spearman correlation, the Kendall correlation is not affected by how far from each other ranks are but only by whether the ranks between observations are equal or not and is thus only appropriate for discrete variables but not defined for continuous variables [61].

\section{Measurement of dopamine release}

Dopamine release was measured by via changes in the GRAB $_{\text {DA4.4 }}$ fluorescence signal in HEK293 cells stably expressing $\mathrm{GRAB}_{\mathrm{DA} 4.4}$. The $\mathrm{GRAB}_{\mathrm{DA} 4.4}$-expressing cells were generously gifted by Dr. Ulrik Gether. The dopamine sensor GRAB $_{\text {DA4.4 }}$ is a genetically encoded fluorescent dopamine sensor, engineered by coupling a conformationally-sensitive circular-permutated EGFP (cpEGFP)

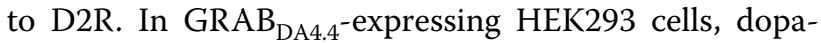
mine binding to the sensor induces a conformational change which results in a robust increase in fluorescence signal via a concentration-dependent manner [122]. The GRAB $_{\text {DA4.4 }}$-expressing HEK 293 cells were maintained in DMEM supplemented with 10\% FBS and 1\% Penicillin/ Streptomycin. Selection pressure for GRAB DA4.4 $_{\text {express- }}$ ing cells was maintained with media containing HygroB $(1 \mathrm{mg} / \mathrm{ml})$, Blasticidin $(0.015 \mathrm{mg} / \mathrm{ml})$, and tetracycline (1:1000). $24 \mathrm{~h}$ before measurement of dopamine release, equal number of GRAB $B_{\text {DA4.4 }}$ expressing cells were plated on coverslips harboring either NAS- or AST-derived dopamine neurons.

Induction of dopamine release was performed via episodic current stimulations (once every $1 \mathrm{~s}$ ) in cellattached or after micro-focal application of agonists when the neuron was held in the whole-cell configuration. To electrically trigger dopamine release, the stimulation pipette was pulled from thin-walled borosilicate glass capillaries $(1.5-\mathrm{mm}$ outer diameter; World Precision Instruments, Sarasota, FL) to a final resistance of 3-4 $\mathrm{M} \Omega$ and filled with aCSF. A MultiClamp 700B amplifier (Molecular Devices, Sunnyvale, CA, USA) was used to obtain cell-attached configuration. Seal resistance in the cell-attached mode was $>4 G \Omega$. An episodic (once every $1 \mathrm{~s})$ and 10-ms depolarizing current pulse (100 $\mathrm{pA}$ ) from the holding potential of $-60 \mathrm{mV}$ was applied. To pharmacologically induce dopamine release current stimulations was not applied.

Blue light $(470 \mathrm{~nm})$ laser illumination was applied for 70 ms using a Digital Mirror Device based pattern illuminator (Mightex Polygon 400, Mightex Systems). For quantification of fluorescence intensity of GRAB ${ }_{\text {DA4.4 }}$-expressing HEK293 cells, experimenter-defined ROIs were created for each cell to exclude both the overlap between adjacent cells and measurement of intensity around the membrane of the cells near the neurons. Background fluorescence was subtracted from all images. Mean intensity over time for each ROI was recorded continuously before and after electronic or focal application (via Pico-spitzer) of agonists. Experiments were performed in the isotonic, isosmotic external solution described above. The baseline fluorescent intensity is defined as the average fluorescent intensity $1 \mathrm{~min}$ (Fig. 11 and Additional file 1: Fig. S5). All values were normalized to the baseline fluorescent intensity. Unless indicated, all electrophysiological and live-imaging experiments were performed in the presence of the following antagonists in the aCSF: $10 \mu \mathrm{M}$ SR-95531 (GABAA receptor), $100 \mathrm{nM}$ CGP 35,348 (GABAB-receptor), $20 \mu \mathrm{M}$ MK-801(NMDA glutamate receptor), $10 \mu \mathrm{M}$ CNQX (AMPA/kainate glutamate receptor) and $1 \mu \mathrm{M} \mathrm{SCH}-23390$ (dopamine $\mathrm{D}_{1}$ receptor).

\section{Statistical and data analysis}

The electrophysiology data was acquired using the Clampex 10 software package (Axon Instruments, Foster City, CA). The data were analyzed offline using pClamp 10. For all experiments, the data are presented as mean \pm SEM. $N$ denotes the number of neurons or cells for each experiment. Statistical significance was assessed using two-tailed Student's $t$ tests or one-way ANOVA. If ANOVA showed statistical significance, all pairwise post hoc analysis was performed using a Tukey's post hoc test. Differences were considered significant at $P<0.05$. * denotes significance $<0.05$. $*$ denotes significance $<0.01$. The coefficient of variation is a measure of the relative spread of the data. It is computed as the standard deviation divided by the mean times $100 \%$.

\section{Supplementary Information}

The online version contains supplementary material available at https://doi. org/10.1186/s40478-021-01203-9.

Additional file 1: Supplemental figure 1-5.

Additional file 2: Results for supplemental data.

Additional file 3: Gene sets enriched for dopamine signaling and processing.

\section{Acknowledgements \\ This study was supported by NIDA Grant: RO1 NS071122, R21 NS103108, National Center for Advancing Translational Sciences of the National Institutes of Health under University of Florida and Florida State University Clinical and Translational Science Awards TL1TR001428 and UL1TR001427. We are very grateful to Dr. Tilo Kunath for providing iPSC lines.}

\section{Authors' contributions}

M.L. designed and performed experiments, analyzed the data, and wrote the manuscript; F.S. performed experiments; P.M. analyzed the data, and wrote the manuscript; D.M. wrote the manuscript; C.M. analyzed the data, and wrote the manuscript; H.K. designed experiments, reviewed the data, and wrote the manuscript. All authors read and approved the final manuscript. 


\section{Declarations}

\section{Competing interests}

The authors do not have a conflict of interest.

\section{Author details}

'Department of Neuroscience, University of Florida, Gainesville, FL 32611, USA 2Environmental and Human Toxicology, University of Florida Genetics Institute, Interdisciplinary Program in Biomedical Sciences Neuroscience, College of Veterinary Medicine, University of Florida, Gainesville, FL 32611, USA.

Received: 11 March 2021 Accepted: 17 May 2021

Published online: 07 June 2021

\section{References}

1. Acampora D, Mazan S, Lallemand Y, Avantaggiato V, Maury M, Simeone A, Brûlet P (1995) Forebrain and midbrain regions are deleted in Otx2/- mutants due to a defective anterior neuroectoderm specification during gastrulation. Development 121(10):3279-3290

2. Adler CH, Sethi KD, Hauser RA, Davis TL, Hammerstad JP, Bertoni J, Taylor RL, Sanchez-Ramos J, O'Brien CF (1997) Ropinirole for the treatment of early Parkinson's disease. Neurology 49(2):393-399

3. Ang SL, Wierda A, Wong D, Stevens KA, Cascio S, Rossant J, Zaret KS (1993) The formation and maintenance of the definitive endoderm lineage in the mouse: involvement of HNF3/forkhead proteins. Development 119(4):1301-1315

4. Anderson DP (1935) Apomorphia hydrochloride. Can Med Assoc J 33(1):74-75

5. Andersson E, Tryggvason U, Deng Q, Friling S, Alekseenko Z, Robert B, Perlmann T, Ericson J (2006) Identification of intrinsic determinants of midbrain dopamine neurons. Cell 124(2):393-405

6. Arenas E, Denham M, Villaescusa JC (2015) How to make a midbrain dopaminergic neuron. Development 142(11):1918-1936

7. Badger JL, Cordero-Llana O, Hartfield EM, Wade-Martins R (2014) Parkinson's disease in a dish: using stem cells as a molecular tool. Neuropharmacology 76(Pt A):88-96

8. Bannon MJ, Michelhaugh SK, Wang J, Sacchetti P (2001) The human dopamine transporter gene: gene organization, transcriptional regulation, and potential involvement in neuropsychiatric disorders. Eur Neuropsychopharmacol 11(6):449-455

9. Bartlett SE, Enquist J, Hopf FW, Lee JH, Gladher F, Kharazia V, Waldhoer M, Mailliard WS, Armstrong R, Bonci A, Whistler JL (2005) Dopamine responsiveness is regulated by targeted sorting of $D 2$ receptors. Proc Natl Acad Sci USA 102(32):11521-11526

10. Bayer HM, Lau B, Glimcher PW (2007) Statistics of midbrain dopamine neuron spike trains in the awake primate. J Neurophysiol 98(3):1428-1439

11. Beaulieu JM, Gainetdinov RR (2011) The physiology, signaling, and pharmacology of dopamine receptors. Pharmacol Rev 63(1):182-217

12. Beckstead MJ, Grandy DK, Wickman K, Williams JT (2004) Vesicula dopamine release elicits an inhibitory postsynaptic current in midbrain dopamine neurons. Neuron 42(6):939-946

13. Beckstead MJ, Williams JT (2007) Long-term depression of a dopamine IPSC. J Neurosci 27(8):2074-2080

14. Ben Gedalya T, Loeb V, Israeli E, Altschuler Y, Selkoe DJ, Sharon R (2009) Alpha-synuclein and polyunsaturated fatty acids promote clathrin-mediated endocytosis and synaptic vesicle recycling. Traffic 10(2):218-234

15. Bernhardt R, Matus A (1982) Initial phase of dendrite growth: evidence for the involvement of high molecular weight microtubule-associated proteins (HMWP) before the appearance of tubulin. J Cell Biol 92(2):589-593

16. Boileau I, Guttman M, Rusjan P, Adams JR, Houle S, Tong J, Hornykiewicz O, Furukawa Y, Wilson AA, Kapur S, Kish SJ (2009) Decreased binding of the D3 dopamine receptor-preferring ligand [11C]-(+)-PHNO in drugnaive Parkinson's disease. Brain 132(Pt 5):1366-1375

17. Bolam JP, Pissadaki EK (2012) Living on the edge with too many mouths to feed: why dopamine neurons die. Mov Disord 27(12):1478-1483
18. Bono F, Mutti V, Devoto P, Bolognin S, Schwamborn JC, Missale C, Fiorentini C (2021) Impaired dopamine D3 and nicotinic acetylcholine receptor membrane localization in iPSCs-derived dopaminergic neurons from two Parkinson's disease patients carrying the LRRK2 G2019S mutation. Neurobiol Aging 99:65-78

19. Bozzi Y, Borrelli E (2006) Dopamine in neurotoxicity and neuroprotection: what do D2 receptors have to do with it? Trends Neurosci 29(3):167-174

20. Bridi JC, Hirth F (2018) Mechanisms of a-synuclein induced synaptopathy in Parkinson's disease. Front Neurosci 12:80

21. Burgess A, Vigneron S, Brioudes E, Labbé JC, Lorca T, Castro A (2010) Loss of human Greatwall results in $\mathrm{G} 2$ arrest and multiple mitotic defects due to deregulation of the cyclin B-Cdc2/PP2A balance. Proc Natl Acad Sci USA 107(28):12564-12569

24. Butler B, Saha K, Rana T, Becker JP, Sambo D, Davari P, Goodwin JS, Khoshbouei H (2015) Dopamine transporter activity is modulated by a-synuclein. J Biol Chem 290(49):29542-29554

23. Calabresi P, Saiardi A, Pisani A, Baik JH, Centonze D, Mercuri NB, Bernardi $G$, Borrelli E (1997) Abnormal synaptic plasticity in the striatum of mice lacking dopamine D2 receptors. J Neurosci 17(12):4536-4544

24. Caceres A, Binder LI, Payne MR, Bender P, Rebhun L, Steward O (1984) Differential subcellular localization of tubulin and the microtubuleassociated protein MAP2 in brain tissue as revealed by immunocytochemistry with monoclonal hybridoma antibodies. J Neurosci 4(2):394-410

25. Cardozo DL (1993) Midbrain dopaminergic neurons from postnatal rat in long-term primary culture. Neuroscience 56(2):409-421

26. Courtois ET, Castillo CG, Seiz EG, Ramos M, Bueno C, Liste I, MartínezSerrano A (2010) In vitro and in vivo enhanced generation of human A9 dopamine neurons from neural stem cells by Bcl-XL. J Biol Chem 285(13):9881-9897

27. Covey DP, Mateo Y, Sulzer D, Cheer JF, Lovinger DM (2017) Endocannabinoid modulation of dopamine neurotransmission. Neuropharmacology 124:52-61

28. Cvetkovska V, Hibbert AD, Emran F, Chen BE (2013) Overexpression of down syndrome cell adhesion molecule impairs precise synaptic targeting. Nat Neurosci 16(6):677-682

29. Dal Toso R, Sommer B, Ewert M, Herb A, Pritchett DB, Bach A, Shivers BD, Seeburg PH (1989) The dopamine D2 receptor: two molecular forms generated by alternative splicing. EMBO J 8(13):4025-4034

30. Decressac M, Mattsson B, Lundblad M, Weikop P, Björklund A (2012) Progressive neurodegenerative and behavioural changes induced by AAV-mediated overexpression of a-synuclein in midbrain dopamine neurons. Neurobiol Dis 45(3):939-953

31. Dehmelt L, Halpain S (2005) The MAP2/Tau family of microtubuleassociated proteins. Genome Biol 6(1):204

32. Devine MJ, Ryten M, Vodicka P, Thomson AJ, Burdon T, Houlden H, Cavaleri F, Nagano M, Drummond NJ, Taanman JW, Schapira AH, Gwinn K, Hardy J, Lewis PA, Kunath T (2011) Parkinson's disease induced pluripotent stem cells with triplication of the a-synuclein locus. Nat Commun 23(2):440

33. Dragicevic E, Schiemann J, Liss B (2015) Dopamine midbrain neurons in health and Parkinson's disease: emerging roles of voltage-gated calcium channels and ATP-sensitive potassium channels. Neuroscience 284:798-814

34. Duby SE, Cotzias GC, Papavasiliou PS, Lawrence WH (1972) Injected apomorphine and orally administered levodopa in Parkinsonism. Arch Neurol 27(6):474-480

35. Eisenreich W, Sommer B, Hartter S, Jost WH (2010) Pramipexole extended release: a novel treatment option in Parkinson's disease. Parkinsons Dis 2010:612619

36. Ferri AL, Lin W, Mavromatakis YE, Wang JC, Sasaki H, Whitsett JA, Ang SL (2007) Foxa1 and Foxa2 regulate multiple phases of midbrain dopaminergic neuron development in a dosage-dependent manner. Development 134(15):2761-2769

37. Ford CP (2014) The role of D2-autoreceptors in regulating dopamine neuron activity and transmission. Neuroscience 282:13-22

38. Friling S, Andersson E, Thompson LH (2009) Efficient production of mesencephalic dopamine neurons by $L m \times 1$ a expression in embryonic stem cells. Proc Natl Acad Sci USA 106:7613-7618 
39. Frost $A$ (2011) Membrane trafficking: decoding vesicle identity with contrasting chemistries. Curr Biol 21(19):R811-813

40. Gazi L, Nickolls SA, Strange PG (2003) Functional coupling of the human dopamine D2 receptor with Gai1, Gai2, Gai3 and Gao G proteins: evidence for agonist regulation of $\mathrm{G}$ protein selectivity. $\mathrm{Br} J \mathrm{Pharmacol}$ 138(5):775-786

41. German CL, Baladi MG, McFadden LM, Hanson GR, Fleckenstein AE (2015) Regulation of the dopamine and vesicular monoamine transporters: pharmacological targets and implications for disease. Pharmacol Rev 67(4):1005-1024

42. Dawson TM, Ko HS, Dawson VL (2010) Genetic animal models of Parkinson's disease. Neuron 66(5):646-661

43. Doss MX, Sachinidis A (2019) Current challenges of iPSC-based disease modeling and therapeutic implications. Cells 8(5):403

44. Giguère N, Delignat-Lavaud B, Herborg F, Voisin A, Li Y, Jacquemet $V$, Anand-Srivastava M, Gether U, Giros B, Trudeau LÉ (2019) Increased vulnerability of nigral dopamine neurons after expansion of their axonal arborization size through D2 dopamine receptor conditional knockout. PLoS Genet 15(8):e1008352

45. Giros B, Jaber M, Jones SR, Wightman RM, Caron MG (1996) Hyperlocomotion and indifference to cocaine and amphetamine in mice lacking the dopamine transporter. Nature 379(6566):606-612

46. Grace AA, Bunney BS (1984) The control of firing pattern in nigral dopamine neurons: burst firing. J Neurosci 4(11):2877-2890

47. Grassi D, Howard S, Zhou M, Diaz-Perez N, Urban NT, Guerrero-Given D, Kamasawa N, Volpicelli-Daley LA, LoGrasso P, Lasmézas CI (2018) Identification of a highly neurotoxic alpha-synuclein species inducing mitochondrial damage and mitophagy in Parkinson's disease. Proc Natl Acad Sci USA 115(11):E2634-E2643

48. Guzman JN, Sánchez-Padilla J, Chan CS, Surmeier DJ (2009) Robust pacemaking in substantia nigra dopaminergic neurons. J Neurosci 29(35):11011-11019

49. Harrison WW, Putnam NM, Shukis $C$, Nguyen E, Reinard $K$, Hundelt $E$, Vardanyan G, Gabai C, Yevseyenkov V (2017) The corneal nerve density in the sub-basal plexus decreases with increasing myopia: a pilot study. Ophthalmic Physiol Opt 37(4):482-488

50. Haston KM, Finkbeiner S (2016) Clinical trials in a dish: the potential of pluripotent stem cells to develop therapies for neurodegenerative diseases. Annu Rev Pharmacol Toxicol 56:489-510

51. Höglinger GU, Rizk P, Muriel MP, Duyckaerts C, Oertel WH, Caille I, Hirsch EC (2004) Dopamine depletion impairs precursor cell proliferation in Parkinson disease. Nat Neurosci 7(7):726-735

52. Howell RD, Dominguez-Lopez S, Ocañas SR, Freeman WM, Beckstead MJ (2020) Female mice are resilient to age-related decline of substantia nigra dopamine neuron firing parameters. Neurobiol Aging 95:195-204

53. Hu W, Qiu B, Guan W, Wang Q, Wang M, Li W, Gao L, Shen L, Huang Y, Xie G, Zhao H, Jin Y, Tang B, Yu Y, Zhao J, Pei G (2015) Direct conversion of normal and Alzheimer's disease human fibroblasts into neuronal cells by small molecules. Cell Stem Cell 17:204-212

54. Inanobe A, Yoshimoto Y, Horio Y, Morishige Kl, Hibino H, Matsumoto S, Tokunaga Y, Maeda T, Hata Y, Takai Y, Kurachi Y (1999) Kurachi Y Characterization of G-protein-gated K+ channels composed of Kir3.2 subunits in dopaminergic neurons of the substantia nigra. J Neurosci 19:1006-1017

55. Ingram SL, Prasad BM, Amara SG (2002) Dopamine transportermediated conductances increase excitability of midbrain dopamine neurons. Nat Neurosci 5(10):971-978

56. Jackson DM, Westlind-Danielsson A (1994) Dopamine receptors: molecular biology, biochemistry and behavioural aspects. Pharmacol Ther 64(2):291-370

57. Jefri M, Bell S, Peng H, Hettige N, Maussion G, Soubannier V, Wu H, Silveira H, Theroux JF, Moquin L, Zhang X, Aouabed Z, Krishnan J, O'Leary LA, Antonyan L, Zhang Y, McCarty V, Mechawar N, Gratton A, Schuppert A, Durcan TM, Fon EA, Ernst C (2020) Stimulation of L-type calcium channels increases tyrosine hydroxylase and dopamine in ventral midbrain cells induced from somatic cells. Stem Cells Transl Med 9(6):697-712

58. Jenerick H (1963) Phase plane trajectories of the muscle spike potential. Biophys J 3(5):363-377
59. Jiang MS, Spicher K, Boulay G, Wang Y, Birnbaumer L (2001) Most central nervous system D2 dopamine receptors are coupled to their effecters by Go. Proc Natl Acad Sci USA 98(6):3577-3582

60. Kann O, Kovács R (2007) Mitochondria and neuronal activity. Am J Physiol Cell Physiol 292(2):C641-657

61. Kendall M (1938) A new measure of rank correlation. Biometrika 30(1-2):81-89

62. Kennedy RT, Jones SR, Wightman RM (1992) Simultaneous measurement of oxygen and dopamine: coupling of oxygen consumption and neurotransmission. Neuroscience 47(3):603-612

63. Kim KM, Nakajima Y, Nakajima S (1995) G protein-coupled inward rectifier modulated by dopamine agonists in cultured substantia nigra neurons. Neuroscience 69(4):1145-1158

64. Kitada T, Asakawa S, Hattori N, Matsumine H, Yamamura Y, Minoshima S, Yokochi M, Mizuno Y, Shimizu N (1998) Mutations in the parkin gene cause autosomal recessive juvenile parkinsonism. Nature 392(6676):605-608

65. Kordower JH, Olanow CW, Dodiya HB, Chu Y, Beach TG, Adler CH, Halliday GM, Bartus RT (2013) Disease duration and the integrity of the nigrostriatal system in Parkinson's disease. Brain 136(Pt 8):2419-2431

66. Kremer Y, Flakowski J, Rohner C, Lüscher C (2020) Context-dependent multiplexing by individual VTA dopamine neurons. J Neurosci 40(39):7489-7509

67. Kriks S, Shim JW, Piao J (2011) Dopamine neurons derived from human ES cells efficiently engraft in animal models of Parkinson's disease. Nature 480:547-551

68. Krupnick JG, Benovic JL (1998) The role of receptor kinases and arrestins in G protein-coupled receptor regulation. Annu Rev Pharmacol Toxicol 38:289-319

69. Lacey MG, Mercuri NB, North RA (1987) Dopamine acts on D2 receptors to increase potassium conductance in neurones of the rat substantia nigra zona compacta. J Physiol 392:397-416

70. Lam HA, Wu N, Cely I, Kelly RL, Hean S, Richter F, Magen I, Cepeda C, Ackerson LC, Walwyn W, Masliah E, Chesselet MF, Levine MS, Maidment NT (2011) Elevated tonic extracellular dopamine concentration and altered dopamine modulation of synaptic activity precede dopamine loss in the striatum of mice overexpressing human alpha-synuclein. J Neurosci Res 89(7):1091-1102

71. Lavine N, Ethier N, Oak JN, Pei L, Liu F, Trieu P, Rebois RV, Bouvier M, Hebert TE, Van Tol HH (2002) G protein-coupled receptors form stable complexes with inwardly rectifying potassium channels and adenylyl cyclase. J Biol Chem 277(48):46010-46019

72. Lee T, Seeman P, Rajput A, Farley IJ, Hornykiewicz O (1978) Receptor basis for dopaminergic supersensitivity in Parkinson's disease. Nature 273(5657):59-61

73. Lee BR, Mu P, Saal DB, Ulibarri C, Dong Y (2008) Homeostatic recovery of downstate-upstate cycling in nucleus accumbens neurons. Neurosci Lett 434(3):282-288

74. Li M, Xu H, Chen G, Sun S, Wang Q, Liu B, Wu X, Zhou L, Chai Z, Sun X, Lu Y, Younus M, Zheng L, Zhu F, Jia H, Chen X, Wang C, Zhou Z (2019) Impaired D2 receptor-dependent dopaminergic transmission in prefrontal cortex of awake mouse model of Parkinson's disease. Brain 142(10):3099-3115

75. Lin M, Sambo D, Khoshbouei H (2016) Methamphetamine regulation of firing activity of dopamine neurons. J Neurosci 36(40):10376-10391

76. Lin M, Colon-Perez LM, Sambo DO, Miller DR, Lebowitz JJ, JimenezRondan F, Cousins RJ, Horenstein N, Aydemir TB, Febo M, Khoshbouei H (2020) Mechanism of manganese dysregulation of dopamine neuronal activity. J Neurosci 40(30):5871-5891

77. Liss B, Roeper J (2001) ATP-sensitive potassium channels in dopaminergic neurons: transducers of mitochondrial dysfunction. News Physiol Sci 16:214-217

78. Lo CA, Kays I, Emran F, Lin TJ, Cvetkovska V, Chen BE (2015) Quantification of protein levels in single living cells. Cell Rep 13(11):2634-2644

79. Lotharius J, Dugan LL, O'Malley KL (1999) Distinct mechanisms underlie neurotoxin-mediated cell death in cultured dopaminergic neurons. J Neurosci 19(4):1284-1293

80. Luo F, Luo S, Qian W, Zhang L, Chen C, Xu M, Wang G, Wang Z, Wang J, Wang W (2020) Developmental deficits and early signs of 
neurodegeneration revealed by PD patient derived dopamine neurons. Stem Cell Res 49:102027

81. Lundblad M, Decressac M, Mattsson B, Björklund A (2012) Impaired neurotransmission caused by overexpression of a-synuclein in nigral dopamine neurons. Proc Natl Acad Sci USA 109(9):3213-3219

82. Mameli-Engvall M, Evrard A, Pons S, Maskos U, Svensson TH, Changeux JP, Faure P (2006) Hierarchical control of dopamine neuron-firing patterns by nicotinic receptors. Neuron 50(6):911-921

83. Marsat G, Pollack GS (2006) A behavioral role for feature detection by sensory bursts. J Neurosci 26(41):10542-10547

84. Margolis EB, Lock H, Hjelmstad GO, Fields HL (2006) The ventral tegmental area revisited: is there an electrophysiological marker for dopaminergic neurons? J Physiol 577(Pt 3):907-924

85. Martin M (2011) Cutadapt removes adapter sequences from highthroughput sequencing reads. EMBnet J 17:10-12

86. Matsuda W, Furuta T, Nakamura KC, Hioki H, Fujiyama F, Arai R, Kaneko $\mathrm{T}$ (2009) Single nigrostriatal dopaminergic neurons form widely spread and highly dense axonal arborizations in the neostriatum. J Neurosci 29(2):444-453

87. Matus A, Bernhardt R, Hugh-Jones T (1981) high molecular weight microtubule-associated proteins are preferentially associated with dendritic microtubules in brain. Proc Natl Acad Sci USA 78(5):3010-3014

88. Meijering E, Jacob M, Sarria JC, Steiner P, Hirling H, Unser M (2004) Design and validation of a tool for neurite tracing and analysis in fluorescence microscopy images. Cytometry A 58(2):167-176

89. Mendez I, Sanchez-Pernaute R, Cooper O, Viñuela A, Ferrari D, Björklund L, Dagher A, Isacson O (2005) Cell type analysis of functional fetal dopamine cell suspension transplants in the striatum and substantia nigra of patients with Parkinson's disease. Brain 128(Pt 7):1498-1510

90. Mercuri NB, Saiardi A, Bonci A, Picetti R, Calabresi P, Bernardi G, Borrelli $E$ (1997) Loss of autoreceptor function in dopaminergic neurons from dopamine D2 receptor deficient mice. Neuroscience 79(2):323-327

91. Metzner W, Koch C, Wessel R, Gabbiani F (1998) Feature extraction by burst-like spike patterns in multiple sensory maps. J Neurosci 18(6):2283-2300

92. Michel PP, Alvarez-Fischer D, Guerreiro S, Hild A, Hartmann A, Hirsch EC (2007) Role of activity-dependent mechanisms in the control of dopaminergic neuron survival. J Neurochem 101(2):289-297

93. Migheli R, Del Giudice MG, Spissu Y, Sanna G, Xiong Y, Dawson TM, Dawson VL, Galioto M, Rocchitta G, Biosa A, Serra PA, Carri MT, Crosio C, laccarino C (2013) LRRK2 affects vesicle trafficking, neurotransmitter extracellular level and membrane receptor localization. PLoS One 8(10):e77198

94. Misonou H, Menegola M, Buchwalder L, Park EW, Meredith A, Rhodes KJ, Aldrich RW, Trimmer JS (2006) Immunolocalization of the $\mathrm{Ca}^{2+}$-activated $\mathrm{K}^{+}$channel Slo1 in axons and nerve terminals of mammalian brain and cultured neurons. J Comp Neurol 496(3):289-302

95. Pacelli C, Giguère N, Bourque MJ, Lévesque M, Slack RS, Trudeau LÉ (2015) Elevated mitochondrial bioenergetics and axonal arborization size are key contributors to the vulnerability of dopamine neurons. Curr Biol 25(18):2349-2360

96. Paladini CA, Robinson S, Morikawa H, Williams JT, Palmiter RD (2003) Dopamine controls the firing pattern of dopamine neurons via a network feedback mechanism. Proc Natl Acad Sci USA 100(5):2866-2871

97. Pearson K (1896) Mathematical contributions to the theory of evolution III. Regression, heredity and panmixia. Philos Trans R Soc Lond B Biol Sci 187:253-318

98. Perez RG, Waymire JC, Lin E, Liu JJ, Guo F, Zigmond JMJ (2002) A role for alpha-synuclein in the regulation of dopamine biosynthesis. J Neurosci 22(8):3090-3099

99. Pingale T, Gupta GL (2020) Classic and evolving animal models in Parkinson's disease. Pharmacol Biochem Behav 199:173060

100. Polymeropoulos MH, Lavedan C, Leroy E, Ide SE, Dehejia A, Dutra A, Pike B, Root H, Rubenstein J, Boyer R, Stenroos ES, Chandrasekharappa S, Athanassiadou A, Papapetropoulos T, Johnson WG, Lazzarini AM, Duvoisin RC, Di lorio G, Golbe LI, Nussbaum RL (1997) Mutation in the alpha-synuclein gene identified in families with Parkinson's disease. Science 276(5321):2045-2047

101. Popko J, Fernandes A, Brites D, Lanier LM (2009) Automated analysis of NeuronJ tracing data. Cytometry A 75:371-376
102. Pucak ML, Grace AA (1994) Evidence that systemically administered dopamine antagonists activate dopamine neuron firing primarily by blockade of somatodendritic autoreceptors. J Pharmacol Exp Ther 271(3):1181-1192

103. Rascol O, Zesiewicz T, Chaudhuri KR, Asgharnejad M, Surmann E, Dohin E, Nilius S, Bauer L (2016) A randomized controlled exploratory pilot study to evaluate the effect of rotigotine transdermal patch on Parkinson's disease-associated chronic pain. J Clin Pharmacol 56(7):852-861

104. Rassu M, Del Giudice MG, Sanna S, Taymans JM, Morari M, Brugnoli A, Frassineti M, Masala A, Esposito S, Galioto M, Valle C, Carri MT, Biosa A, Greggio E, Crosio C, laccarino C (2017) Role of LRRK2 in the regulation of dopamine receptor trafficking. PLoS One 12(6):e0179082

105. Reiner O, Sapir T, Parichha A (2020) Using multi-organ culture systems to study Parkinson's disease. Mol Psychiatry 5:1-11

106. Rinne UK, Bracco F, Chouza C, Dupont E, Gershanik O, Marti Masso JF, Montastruc JL, Marsden CD, Dubini A, Orlando N, Grimaldi R (1997) Cabergoline in the treatment of early Parkinson's disease: results of the first year of treatment in a double-blind comparison of cabergoline and levodopa. The PKDS009 Collaborative Study Group. Neurology 48(2):363-368

107. Robinson BG, Bunzow JR, Grimm JB, Lavis LD, Dudman JT, Brown J, Neve KA, Williams JT (2017) Desensitized D2 autoreceptors are resistant to trafficking. Sci Rep 7(1):4379

108. Saha K, Sambo D, Richardson BD, Lin LM, Butler B, Villarroel L, Khoshbouei $H$ (2014) Intracellular methamphetamine prevents the dopamine-induced enhancement of neuronal firing. J Biol Chem 289(32):22246-22257

109. Samata B, Doi D, Nishimura K, Kikuchi T, Watanabe A, Sakamoto Y, Kakuta J, Ono Y, Takahashi J (2016) Purification of functional human ES and iPSC-derived midbrain dopaminergic progenitors using LRTM1. Nat Commun 7:13097

110. Sambo DO, Lin M, Owens A, Lebowitz JJ, Richardson B, Jagnarine DA, Shetty M, Rodriquez M, Alonge T, Ali M, Katz J, Yan L, Febo M, Henry LK, Bruijnzeel AW, Daws L, Khoshbouei H (2017) The sigma-1 receptor modulates methamphetamine dysregulation of dopamine neurotransmission. Nat Commun 8(1):2228

111. Sanders LH, Laganière J, Cooper O, Mak SK, Vu BJ, Huang YA, Paschon DE, Vangipuram M, Sundararajan R, Urnov FD, Langston JW, Gregory PD, Zhang HS, Greenamyre JT, Isacson O, Schüle B (2014) LRRK2 mutations cause mitochondrial DNA damage in iPSC-derived neural cells from Parkinson's disease patients: reversal by gene correction. Neurobiol Dis 62:381-386

112. Schiemann J, Schlaudraff F, Klose V, Bingmer M, Seino S, Magill PJ, Zaghloul KA, Schneider G, Liss B, Roeper J (2012) K-ATP channels in dopamine substantia nigra neurons control bursting and noveltyinduced exploration. Nat Neurosci 15(9):1272-1280

113. Shimura H, Schlossmacher MG, Hattori N, Frosch MP, Trockenbacher A, Schneider R, Mizuno Y, Kosik KS, Selkoe DJ (2001) Ubiquitination of a new form of alpha-synuclein by parkin from human brain: implications for Parkinson's disease. Science 293(5528):263-269

114. Silani V, Mariani D, Donato FM, Ghezzi C, Mazzucchelli F, Buscaglia M, Pardi G, Scarlato G (1994) Development of dopaminergic neurons in the human mesencephalon and in vitro effects of basic fibroblast growth factor treatment. Exp Neurol 128(1):59-76

115. Simon HH, Saueressig H, Wurst W, Goulding MD, O'Leary DD (2001) Fate of midbrain dopaminergic neurons controlled by the engrailed genes. $J$ Neurosci 21(9):3126-3134

116. Sidhu A, Wersinger C, Vernier $P$ (2004) alpha-Synuclein regulation of the dopaminergic transporter: a possible role in the pathogenesis of Parkinson's disease. FEBS Lett 565(1-3):1-5

117. Smidt MP, Asbreuk CH, Cox JJ, Chen H, Johnson RL, Burbach JP (2000) A second independent pathway for development of mesencephalic dopaminergic neurons requires Lmx1b. Nat Neurosci 3(4):337-341

118. Smith SK, Lee CA, Dausch ME, Horman BM, Patisaul HB, McCarty GS, Sombers LA (2017) Simultaneous voltammetric measurements of glucose and dopamine demonstrate the coupling of glucose availability with increased metabolic demand in the rat striatum. ACS Chem Neurosci 8(2):272-280

119. Soldner F, Laganière J, Cheng AW, Hockemeyer D, Gao Q, Alagappan R, Khurana V, Golbe LI, Myers RH, Lindquist S, Zhang L, Guschin D, Fong LK, Vu BJ, Meng X, Urnov FD, Rebar EJ, Gregory PD, Zhang HS, Jaenisch 
R (2011) Generation of isogenic pluripotent stem cells differing exclusively at two early onset Parkinson point mutations. Cell 146(2):318-331

120. Spearman C (1907) Demonstration of formulæ for true measurement of correlation. Am J Psychol 18(2):161-169

121. Stark AJ, Smith CT, Lin YC, Petersen KJ, Trujillo P, van Wouwe NC, Kang H, Donahue MJ, Kessler RM, Zald DH, Claassen DO (2018) Nigrostriatal and mesolimbic $D_{2 / 3}$ receptor expression in parkinson's disease patients with compulsive reward-driven behaviors. J Neurosci 38(13):3230-3239

122. Sun F, Zeng J, Jing $M$, Zhou J, Feng J, Owen SF, Luo Y, Li F, Wang H, Yamaguchi T, Yong Z, Gao Y, Peng W, Wang L, Zhang S, Du J, Lin D, Xu M, Kreitzer AC, Cui G, Li YA (2018) Genetically encoded fluorescent sensor enables rapid and specific detection of dopamine in flies, fish, and mice. Cell 174(2):481-496

123. Swant J, Goodwin JS, North A, Ali AA, Gamble-George J, Chirwa S, Khoshbouei H (2011) a-Synuclein stimulates a dopamine transporterdependent chloride current and modulates the activity of the transporter. J Biol Chem 286(51):43933-43943

124. Tepper JM, Sawyer SF (1987) Groves PM Electrophysiologically identified nigral dopaminergic neurons intracellularly labeled with HRP: light-microscopic analysis. J Neurosci 7(9):2794-2806

125. Thompson L, Barraud P, Andersson E, Kirik D, Björklund A (2005) Identification of dopaminergic neurons of nigral and ventral tegmental area subtypes in grafts of fetal ventral mesencephalon based on cell morphology, protein expression, and efferent projections. J Neurosci 25:6467-6477

126. Tong Y, Pisani A, Martella G, Karouani M, Yamaguchi H, Pothos EN, Shen J (2009) R1441C mutation in LRRK2 impairs dopaminergic neurotransmission in mice. Proc Natl Acad Sci USA 106(34):14622-14627

127. Trapnell C, Williams BA, Pertea G, Mortazavi A, Kwan G, van Baren MJ, Salzberg SL, Wold BJ, Pachter L (2010) Transcript assembly and quantification by RNA-Seq reveals unannotated transcripts and isoform switching during cell differentiation. Nat Biotechnol 28(5):511-515
128. Urbánek P, Fetka I, Meisler MH, Busslinger M (1997) Cooperation of Pax2 and Pax5 in midbrain and cerebellum development. Proc Natl Acad Sci USA 94(11):5703-5708

129. Viotti M, Nowotschin S, Hadjantonakis AK (2014) SOX17 links gut endoderm morphogenesis and germ layer segregation. Nat Cell Biol 16(12):1146-1156

130. Wersinger C, Sidhu A (2003) Attenuation of dopamine transporter activity by alpha-synuclein. Neurosci Lett 340(3):189-192

131. Wong YC, Krainc D (2017) a-synuclein toxicity in neurodegeneration: mechanism and therapeutic strategies. Nat Med 23(2):1-13

132. Xi J, Liu Y, Liu H (2012) Specification of midbrain dopamine neurons from primate pluripotent stem cells. Stem Cells 30:1655-1663

133. Yang P, Perlmutter JS, Benzinger TLS, Morris JC, Xu J (2020) Dopamine D3 receptor: a neglected participant in Parkinson Disease pathogenesis and treatment? Ageing Res Rev 57:100994

134. Yu S, Uéda K, Chan P (2005) Alpha-synuclein and dopamine metabolism. Mol Neurobiol 31(1-3):243-254

135. Zaghloul KA, Blanco JA, Weidemann CT, McGill K, Jaggi JL, Baltuch GH, Kahana MJ (2009) Human substantia nigra neurons encode unexpected financial rewards. Science 323(5920):1496-1499

136. Zervas M, Millet S, Ahn S, Joyner AL (2004) Cell behaviors and genetic lineages of the mesencephalon and rhombomere 1. Neuron 43(3):345-357

137. Zetterström RH, Solomin L, Jansson L, Hoffer BJ, Olson L, Perlmann T (1997) Dopamine neuron agenesis in Nurr1-deficient mice. Science 276(5310):248-250

\section{Publisher's Note}

Springer Nature remains neutral with regard to jurisdictional claims in published maps and institutional affiliations.
Ready to submit your research? Choose BMC and benefit from:

- fast, convenient online submission

- thorough peer review by experienced researchers in your field

- rapid publication on acceptance

- support for research data, including large and complex data types

- gold Open Access which fosters wider collaboration and increased citations

- maximum visibility for your research: over $100 \mathrm{M}$ website views per year

At BMC, research is always in progress.

Learn more biomedcentral.com/submissions 